\title{
SPARTAN: a global network to evaluate and enhance satellite-based estimates of ground-level particulate matter for global health applications
}

G. Snider ${ }^{1}$, C. L. Weagle ${ }^{2}$, R. V. Martin ${ }^{1,2,3}$, A. van Donkelaar ${ }^{1}$, K. Conrad ${ }^{1}$, D. Cunningham ${ }^{1}$, C. Gordon ${ }^{1}$, M. Zwicker ${ }^{1}$, C. Akoshile ${ }^{4}$, P. Artaxo ${ }^{5}$, N. X. Anh ${ }^{6}$, J. Brook $^{7}$, J. Dong ${ }^{8}$, R. M. Garland ${ }^{9}$, R. Greenwald ${ }^{10}$, D. Griffith ${ }^{11}$, K. He ${ }^{8}$, B. N. Holben ${ }^{12}$, R. Kahn ${ }^{12}$, I. Koren ${ }^{13}$, N. Lagrosas ${ }^{14}$, P. Lestari ${ }^{15}$, Z. Ma ${ }^{10}$, J. Vanderlei Martins $^{16}$, E. J. Quel ${ }^{17}$, Y. Rudich ${ }^{13}$, A. Salam ${ }^{18}$, S. N. Tripathi ${ }^{19}$, C. Yu ${ }^{10}$, Q. Zhang ${ }^{8}$, Y. Zhang ${ }^{8}$, M. Brauer ${ }^{20}$, A. Cohen ${ }^{21}$, M. D. Gibson ${ }^{22}$, and Y. Liu ${ }^{10}$

${ }^{1}$ Department of Physics and Atmospheric Science, Dalhousie University, Halifax, Nova Scotia, Canada

${ }^{2}$ Department of Chemistry, Dalhousie University, Halifax, Nova Scotia, Canada

${ }^{3}$ Harvard-Smithsonian Center for Astrophysics, Cambridge, Massachusetts, USA

${ }^{4}$ Department of Physics, University of Ilorin, Ilorin, Nigeria

${ }^{5}$ Instituto de Física, Universidade de São Paulo, Rua do Matão, Travessa R, 187, São Paulo, Brazil

${ }^{6}$ Institute of Geophysics, Vietnam Academy of Science and Technology, Hanoi, Vietnam

${ }^{7}$ Department of Public Health Sciences, University of Toronto, Toronto, Ontario, Canada

${ }^{8}$ Center for Earth System Science, Tsinghua University, Beijing, China

${ }^{9}$ Unit for Environmental Science and Management, North-West University, Potchefstroom, South Africa

${ }^{10}$ Rollins School of Public Health, Emory University, 1518 Clifton Road NE, Atlanta, Georgia, USA

${ }^{11}$ Council for Scientific and Industrial Research (CSIR), Pretoria, South Africa

${ }^{12}$ Earth Science Division, NASA Goddard Space Flight Center, Greenbelt, Maryland, USA

${ }^{13}$ Department of Earth and Planetary Sciences, Weizmann Institute, Rehovot 76100, Israel

${ }^{14}$ Manila Observatory, Ateneo de Manila University campus, Quezon City, Philippines

${ }^{15}$ Faculty of Civil and Environmental Engineering, Institute of Technology Bandung (ITB), JL. Ganesha No.10, Bandung 40132, Indonesia

${ }^{16}$ Department of Physics and Joint Center for Earth Systems Technology, University of Maryland, Baltimore County, Baltimore, Maryland, USA

${ }^{17}$ UNIDEF (CITEDEF-CONICET) Juan B. de la Salle 4397 - B1603ALO Villa Martelli, Buenos Aires, Argentina

${ }^{18}$ Department of Chemistry, University of Dhaka, Dhaka - 1000, Bangladesh

${ }^{19}$ Center for Environmental Science and Engineering, Indian Institute of Technology, Kanpur, India

${ }^{20}$ School of Population and Public Health, University of British Columbia, Vancouver, British Columbia, Canada

${ }^{21}$ Health Effects Institute, 101 Federal Street Suite 500, Boston, Massachusetts, USA

${ }^{22}$ Department of Process Engineering and Applied Science, Dalhousie University, Halifax, Nova Scotia, Canada

Correspondence to: G. Snider (graydon.snider@ dal.ca)

Received: 24 June 2014 - Published in Atmos. Meas. Tech. Discuss.: 23 July 2014

Revised: 18 November 2014 - Accepted: 9 January 2015 - Published: 30 January 2015 
Abstract. Ground-based observations have insufficient spatial coverage to assess long-term human exposure to fine particulate matter $\left(\mathrm{PM}_{2.5}\right)$ at the global scale. Satellite remote sensing offers a promising approach to provide information on both short- and long-term exposure to $\mathrm{PM}_{2.5}$ at local-toglobal scales, but there are limitations and outstanding questions about the accuracy and precision with which groundlevel aerosol mass concentrations can be inferred from satellite remote sensing alone. A key source of uncertainty is the global distribution of the relationship between annual average $\mathrm{PM}_{2.5}$ and discontinuous satellite observations of columnar aerosol optical depth (AOD). We have initiated a global network of ground-level monitoring stations designed to evaluate and enhance satellite remote sensing estimates for application in health-effects research and risk assessment. This Surface PARTiculate mAtter Network (SPARTAN) includes a global federation of ground-level monitors of hourly $\mathrm{PM}_{2.5}$ situated primarily in highly populated regions and collocated with existing ground-based sun photometers that measure AOD. The instruments, a three-wavelength nephelometer and impaction filter sampler for both $\mathrm{PM}_{2.5}$ and $\mathrm{PM}_{10}$, are highly autonomous. Hourly $\mathrm{PM}_{2.5}$ concentrations are inferred from the combination of weighed filters and nephelometer data. Data from existing networks were used to develop and evaluate network sampling characteristics. SPARTAN filters are analyzed for mass, black carbon, watersoluble ions, and metals. These measurements provide, in a variety of regions around the world, the key data required to evaluate and enhance satellite-based $\mathrm{PM}_{2.5}$ estimates used for assessing the health effects of aerosols. Mean $\mathrm{PM}_{2.5}$ concentrations across sites vary by more than 1 order of magnitude. Our initial measurements indicate that the ratio of AOD to ground-level $\mathrm{PM}_{2.5}$ is driven temporally and spatially by the vertical profile in aerosol scattering. Spatially this ratio is also strongly influenced by the mass scattering efficiency.

\section{Introduction, motivation, and problem definition}

Particulate matter with a median aerodynamic diameter less than $2.5 \mu \mathrm{m}\left(\mathrm{PM}_{2.5}\right)$ is a robust indicator of mortality and other adverse health effects associated with ambient air pollution (Chen et al., 2008; Laden et al., 2006). Research on long-term exposure to ambient $\mathrm{PM}_{2.5}$ has documented serious adverse health effects, including increased mortality from chronic cardiovascular disease, respiratory disease, and lung cancer (WHO, 2005). The Global Burden of Disease 2010 estimated that outdoor $\mathrm{PM}_{2.5}$ caused $3.2 \pm 0.4$ million deaths $(3.0 \%$ of all deaths) and $76(+9.0,-8.1)$ million years of lost healthy life on a global scale in the year 2010 (Lim et al., 2012). Given the implications and uncertainties of this estimate, additional attention is needed to improve global estimates of $\mathrm{PM}_{2.5}$ exposure.
Routine measurements of long-term average concentrations of $\mathrm{PM}_{2.5}$ have until very recently been generally limited to North America and Europe. Research on adverse $\mathrm{PM}_{2.5}$ health effects can only be conducted where information exists about population exposures. As a result, the epidemiologic evidence of chronic exposure to fine particles comes primarily from studies conducted in low- $\mathrm{PM}_{2.5}$ locations. Elsewhere in the world, in regions thought to have the highest ground-level concentrations of $\mathrm{PM}_{2.5}$ (including large parts of Asia, Africa, and the Middle East) there is little or no long-term surface monitoring of $\mathrm{PM}_{2.5}$ (Brauer et al., 2011; Friedl et al., 2010). Research on the health effects of longterm $\mathrm{PM}_{2.5}$ exposure in these regions has been limited (HEI, 2010). Risk assessments such as the Global Burden of Disease (Lim et al., 2012) have had to rely on uncertain extrapolation of North American and European epidemiologic study results. Despite recent increases in $\mathrm{PM}_{2.5}$ surface monitoring in some locations such as in parts of Asia, ground-level measurements of $\mathrm{PM}_{2.5}$ are still far too sparse in terms of spatial and temporal coverage to be used in long-term exposure estimates or to supplement satellite remote sensing. Aerosol concentration estimates from chemical transport models are uncertain in highly populated areas (Anenberg et al., 2010; Fang et al., 2013; Punger and West, 2013). Existing PM $_{10}$ measurements (e.g. Brauer et al., 2011) and airport observations of visibility (Husar et al., 2000) can only partially address the needs of global-scale health impact assessment. Global publicly available $\mathrm{PM}_{2.5}$ data are needed in multiple urban centres and highly populated rural zones for epidemiologic research and health-based risk assessments.

Satellite remote sensing of ground-level particulate matter, when combined with external constraints of aerosol vertical profiles from chemical transport models, has emerged as a promising solution to this need (van Donkelaar et al., 2010). This hybridized detection method is being increasingly applied in epidemiologic research and risk assessment (e.g. Crouse et al., 2012). However, remote sensing continues to require additional validation and analysis to support its widespread use for health-related applications on a global scale. There are outstanding questions about the accuracy and precision with which ground-level long-term $\mathrm{PM}_{2.5}$ mass concentrations can be inferred from discontinuous aerosol optical depth (AOD) observations (Hoff and Christopher, 2009; Paciorek and Liu, 2009). Factors that affect the relationship of satellite AOD observations to longterm $\mathrm{PM}_{2.5}$ include the aerosol vertical profile, the conversion of ambient extinction to dry $\mathrm{PM}_{2.5}$ mass, $\mathrm{PM}_{2.5}$ diurnal variation, and cloud-free sampling biases. Measurements of ground-level $\mathrm{PM}_{2.5}$ collocated with AOD measurements are needed to evaluate model calculations of $\mathrm{PM}_{2.5}$ / AOD ratios and, in turn, improve estimates of surface $\mathrm{PM}_{2.5}$ from satellite AOD retrievals. Composition information is also needed both because a variety of studies link $\mathrm{PM}_{2.5}$ composition to health outcomes (e.g. Bell et al., 2011; Lippmann, 2014) and for the ability to influence the mass extinction efficiency 
(e.g. McInnes et al., 1998; Mishra and Tripathi, 2008). Particulate matter composition is also useful for source attribution (Kong et al., 2010) and for understanding aerosol formation processes (e.g. Hand et al., 2012).

Accurate AOD is measured from a network of groundbased sun photometers. The Aerosol Robotic Network (AERONET) is a remarkably successful federation of sun photometer stations that provides global, long-term, continuous, and publicly available data, in particular of AOD (Holben et al., 1998). AERONET provides temporally resolved cloud-free measurements during daylight hours at 0.01 to 0.02 mid-visible AOD accuracy and is extensively used for satellite validation (e.g. Remer et al., 2005). Other sun photometer networks provide additional measurement locations (e.g. Kahn et al., 2004). To our knowledge, prior to our initiative, no sites anywhere in the world routinely measured and made publicly available collocated measurements of AOD, $\mathrm{PM}_{2.5}$, and $\mathrm{PM}_{2.5}$ composition.

In this paper we describe the development and measurement approaches of the Surface PARTiculate mAtter Network (SPARTAN), which is specifically designed to evaluate and enhance satellite-based estimates of ground-level particulate matter and to reduce uncertainties in their use for global health applications. SPARTAN collects both midday aerosol optical measurements needed to compare with satellite observation times and the $24 \mathrm{~h} \mathrm{PM}_{2.5}$ averages relevant for health studies. SPARTAN is designed to be applicable to all satellite instruments that are used for AOD retrievals including the MODIS, MISR, and VIIRS instruments. This paper provides an overview of steps toward the development of SPARTAN. Section 2 describes the site-selection process and prioritization. Section 3 provides a general overview of SPARTAN instrumentation. Section 4 presents initial results.

\section{SPARTAN site selection and prioritization}

The overarching purpose of SPARTAN is to evaluate and enhance satellite remote sensing estimates of ground-level $\mathrm{PM}_{2.5}$ in populated areas. Given this objective, we used several criteria to identify priority SPARTAN sites: (i) high population density is desirable for relevance to global public health; (ii) collocation with existing sun photometers provides high-quality measurements of AOD currently used for satellite evaluation; (iii) locations should span a wide range of $\mathrm{PM}_{2.5}$ concentrations and composition; (iv) locations are preferred where satellite-based $\mathrm{PM}_{2.5}$ estimates have higher uncertainty or where little publicly available $\mathrm{PM}_{2.5}$ data exist; (v) locations should represent spatial scales of typical satellite products of $>3 \mathrm{~km} \times 3 \mathrm{~km}$ (Appendix A1.1 assesses the spatial representativeness of single measurement sites compared with satellite observation area); (vi) safety of personnel and equipment is also considered.

Figure 1 shows current and potential sites spanning regions with low (e.g. Manila and Halifax) to high (e.g. Bei-
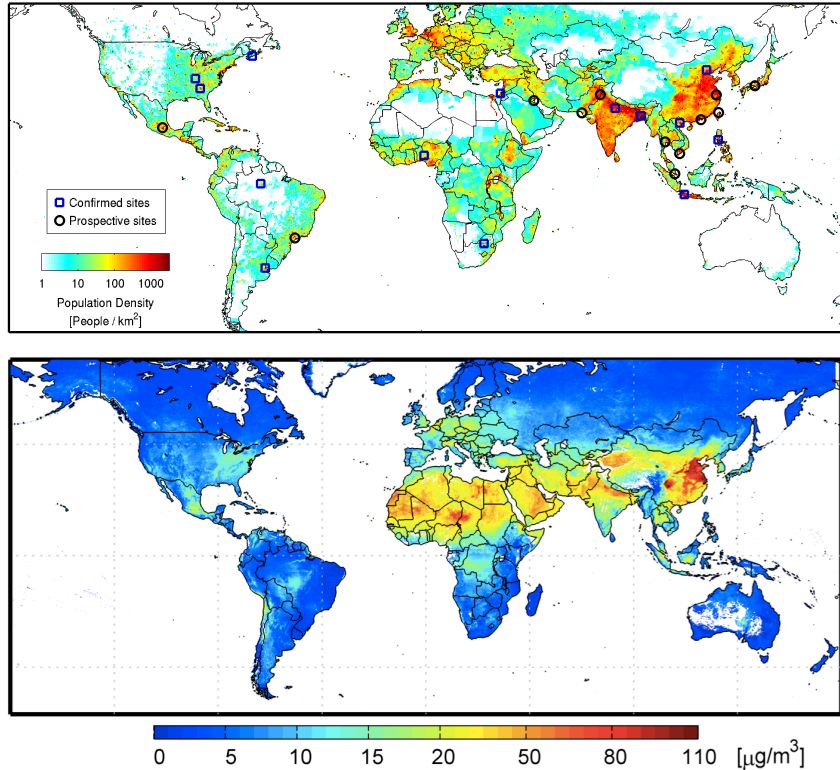

Figure 1. Top: global population density for 2010 (GPWv3, 2005). Black circles indicate priority sites for SPARTAN. Blue squares indicate confirmed sites. Table 1 contains further site information. Bottom: satellite-derived $\mathrm{PM}_{2.5}\left(\mu \mathrm{g} \mathrm{m}^{-3}\right)$ averaged from 2001 to 2006 (at $10 \mathrm{~km} \times 10 \mathrm{~km}$ resolution) as inferred from AOD from the MODIS and MISR satellite instruments and coincident GEOSChem CTM aerosol vertical profiles (van Donkelaar et al., 2010). White space indicates water or locations containing $<50$ valid AOD retrievals during this period.

jing and Kanpur) $\mathrm{PM}_{2.5}$. Locations include regions impacted by biomass burning (e.g. West Africa, South America), biofuel use (e.g. south Asia), monsoonal conditions (e.g. West Africa, Southeast Asia), and mineral dust (e.g. West Africa, Middle East). Exact site placement depends on specific partnerships and the availability of resources and personnel. Table 1 lists confirmed host sites to date. The sites of Halifax, Atlanta, and Mammoth Cave are included for instrument inter-comparison purposes.

\section{SPARTAN instrumentation}

\subsection{General overview}

SPARTAN is composed of ground-based instruments that measure fine-particle concentrations and allow for the determination of some compositional features (i.e. water-soluble ions, black carbon, and major metals). Our primary focus is on determining $\mathrm{PM}_{2.5}$ mass. We subdivide this goal into estimating hourly, $24 \mathrm{~h}$ mean, and long-term (annual and seasonal) concentrations. Daily mean $\mathrm{PM}_{2.5}$ is compared and related with total column AOD measurements during daytime satellite overpass times. Coarse aerosol mass, defined as $\mathrm{PM}_{\mathrm{c}} \equiv \mathrm{PM}_{10}-\mathrm{PM}_{2.5}$, is measured to assess $\mathrm{PM}_{10}$ concen- 
Table 1. Site information for confirmed SPARTAN station locations.

\begin{tabular}{|c|c|c|c|c|c|c|c|c|c|c|}
\hline \multirow{2}{*}{$\begin{array}{l}\text { Host name, } \\
\text { country }\end{array}$} & \multicolumn{2}{|c|}{$\begin{array}{l}\text { Site } \\
\text { coordinates }\end{array}$} & \multicolumn{2}{|c|}{$\begin{array}{c}\text { Local pop. } \\
\text { density }^{\mathrm{a}} \\
\text { (persons } \mathrm{km}^{-2} \text { ) }\end{array}$} & \multirow{2}{*}{$\begin{array}{l}\text { Satellite } \\
\mathrm{PM}_{2.5} \\
\left(\mu \mathrm{g} \mathrm{m}^{-3}\right)^{\mathrm{b}}\end{array}$} & \multirow{2}{*}{$\begin{array}{l}\text { Temp. }{ }^{\mathrm{c}} \\
\left({ }^{\circ} \mathrm{C}\right) \\
{[\text { high/low }]}\end{array}$} & \multirow{2}{*}{$\begin{array}{l}\text { Annual } \\
\mathrm{RH}^{\mathrm{c}}(\%)\end{array}$} & \multirow{2}{*}{$\begin{array}{l}\text { Elevation } \\
\text { (sea } \\
\text { level//above } \\
\text { ground) }(\mathrm{m})\end{array}$} & \multirow{2}{*}{$\begin{array}{l}\text { Site description, } \\
\text { location }\end{array}$} & \multirow[t]{2}{*}{ Start date } \\
\hline & Lat & Long & $\begin{array}{l}0.25^{\circ} \times \\
0.25^{\circ}\end{array}$ & $\begin{array}{l}10 \mathrm{~km} \times \\
10 \mathrm{~km}\end{array}$ & & & & & & \\
\hline Bandung, Indonesia & -6.888 & 107.610 & 1600 & 16,000 & 14 & $27 / 18$ & 73 & $780 / / 20$ & $\begin{array}{l}\text { Rooftop of university } \\
\text { building, urban }\end{array}$ & January 2014 \\
\hline $\begin{array}{l}\text { CITEDEF, } \\
\text { Argentina }\end{array}$ & -34.555 & -58.506 & 1500 & 12,000 & 9 & $23 / 14$ & 72 & $30 / / 5$ & $\begin{array}{l}\text { Rooftop of one-story } \\
\text { building, urban }\end{array}$ & October 2014 \\
\hline $\begin{array}{l}\text { CSIR, Pretoria, } \\
\text { South Africa }\end{array}$ & -25.751 & 28.279 & 1400 & 1900 & 12 & $23 / 13$ & 58 & $1420 / / \mathrm{TBD}$ & $\begin{array}{l}\text { Rooftop of university } \\
\text { building, urban }\end{array}$ & $\begin{array}{l}\text { TBD, early } \\
2015\end{array}$ \\
\hline $\begin{array}{l}\text { Dalhousie } \\
\text { University, Canada }\end{array}$ & 44.638 & -63.594 & 500 & 1200 & 7 & $10 / 1$ & 79 & $40 / / 20$ & $\begin{array}{l}\text { Rooftop of university } \\
\text { building, suburban }\end{array}$ & January 2013 \\
\hline $\begin{array}{l}\text { Emory University, } \\
\text { United States }\end{array}$ & 33.688 & -84.290 & 890 & 1800 & 17 & $22 / 11$ & 67 & $250 / / 2$ & $\begin{array}{l}\text { Emory supersite, } \\
\text { ground level, rural }\end{array}$ & January 2013 \\
\hline $\begin{array}{l}\text { Indian Institute of } \\
\text { Technology Kanpur, } \\
\text { India }\end{array}$ & 26.519 & 80.232 & 1000 & 3100 & 52 & $32 / 19$ & 66 & $130 / / 10$ & $\begin{array}{l}\text { Rooftop near } \\
\text { university airport, } \\
\text { rural }\end{array}$ & $\begin{array}{l}\text { November } \\
2013\end{array}$ \\
\hline Mammoth Cave & 37.132 & -86.148 & 20 & 20 & 13 & $20 / 7$ & 72 & $235 / / 2$ & Farm field, rural & June 2014 \\
\hline $\begin{array}{l}\text { Manila Observatory, } \\
\text { Philippines }\end{array}$ & 14.635 & 121.077 & 9600 & 9100 & 16 & $31 / 23$ & 79 & $60 / / 10$ & $\begin{array}{l}\text { Roof of Manila } \\
\text { Observatory, } \\
\text { suburban }\end{array}$ & January 2014 \\
\hline Manaus $^{\mathrm{d}}$, Brazil & -2.594 & -60.209 & 140 & 150 & 5 & $30 / 23$ & 83 & $110 / / \mathrm{TBD}$ & TBD & $\begin{array}{l}\text { TBD, early } \\
2015\end{array}$ \\
\hline Nes Ziona, Israel & 31.924 & 34.788 & 1600 & 1400 & 21 & $25 / 14$ & 70 & $20 / / 10$ & $\begin{array}{l}\text { University building } \\
\text { rooftop, suburban }\end{array}$ & January 2015 \\
\hline $\begin{array}{l}\text { Tsinghua University, } \\
\text { China }\end{array}$ & 39.997 & 116.329 & 3000 & 5600 & 96 & $17 / 7$ & 57 & $60 / / 20$ & Rooftop, urban & January 2013 \\
\hline $\begin{array}{l}\text { University of Dhaka, } \\
\text { Bangladesh }\end{array}$ & 23.728 & 90.398 & 2900 & 51,000 & 42 & $31 / 22$ & 75 & $20 / / 20$ & $\begin{array}{l}\text { University rooftop, } \\
\text { urban, }\end{array}$ & $\begin{array}{l}\text { November } \\
2013\end{array}$ \\
\hline $\begin{array}{l}\text { University of Ilorin, } \\
\text { Nigeria }\end{array}$ & 8.481 & 4.526 & 360 & 1100 & 17 & $27 / 25$ & 57 & $330 / / 10$ & $\begin{array}{l}\text { University building } \\
\text { rooftop, suburban }\end{array}$ & April 2014 \\
\hline $\begin{array}{l}\text { Vietnam Academy } \\
\text { of Science and } \\
\text { Technology, } \\
\text { Vietnam }\end{array}$ & 21.048 & 105.801 & 3500 & 5700 & 46 & $26 / 21$ & 80 & $10 / / \mathrm{TBD}$ & $\begin{array}{l}\text { University building } \\
\text { rooftop, urban }\end{array}$ & $\begin{array}{l}\text { TBD, early } \\
2015\end{array}$ \\
\hline
\end{tabular}

trations. Coarse mass provides additional information on the particle size distribution of relevance for both aerosol optical properties and health effects. A major consideration for the instrumentation is capability for near-autonomous operation. Cost efficiencies are considered, given the grass-roots nature of this network.

Each SPARTAN site includes a combination of continuous monitoring by nephelometry and mass concentration from sampling on filters. Nephelometer backscatter and total light scatter at three wavelengths provide high temporal resolution and some information on particle size. We constrain nephelometer light scattering with filter-based measurements over multi-day intervals; hence the combination of these measurements yields estimates of hourly $\mathrm{PM}_{2.5}$ values.
All SPARTAN instruments to date have been designed and manufactured by AirPhoton, LLC (www.airphoton.com). Attributes of these instruments include low maintenance, portability, and field readiness. Installation is straightforward; both the nephelometer and air sampler mount directly to a secure support pole. Sections 3.2 and 3.3 summarize the most recent instrument designs, but they will likely be modified as the network matures. Total power consumption is minimal $(34 \mathrm{~W})$ and the instruments are being successfully operated in Nigeria using a solar panel and battery. Martins et al. (2015) will provide more detail about the instrument characteristics and performance. 


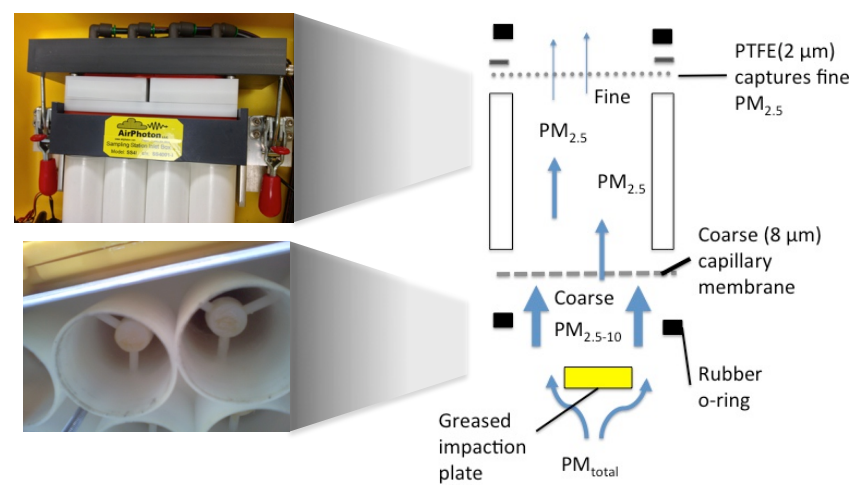

Figure 2. Diagram of AirPhoton filter assembly. The aerosol/air stream first passes through a bug screen followed by a greased impaction plate that removes particulates larger than $\sim 10 \mu \mathrm{m}$ diameter. Impaction plates are re-greased prior to loading a new cartridge. The $8 \mu \mathrm{m}$ capillary membrane filter then traps coarse $\mathrm{PM}_{\mathrm{C}} \equiv\left(\mathrm{PM}_{10}-\mathrm{PM}_{2.5}\right)$ particulates. A $2 \mu \mathrm{m}$ PTFE filter traps fine $\mathrm{PM}_{2.5}$. Blue arrows indicate the direction of airflow (flow rate is $4 \mathrm{~L} \mathrm{~min}^{-1}$ ). Useable filter diameter on which PM is collected is $19 \mathrm{~mm}$, resulting in PTFE and capillary membrane face velocities of $23.5 \mathrm{~cm} \mathrm{~s}^{-1}$. Capillary porosity is $5 \%$.

\subsection{Impaction measurements: concept and strategy}

Filter-based measurements are collected using an AirPhoton SS4i automated air sampler. Each station houses a removable filter cartridge inside a weather-resistant Pelican case such that the filter inlet faces downwards. Airflow and back pressure are logged every $15 \mathrm{~s}$ onto a memory card with capacity for 2 or more years of data. The eight-slot filter cartridge protects the filters during transport to and from the field and reduces the frequency of site visits. Sampled cartridges are mailed to the central SPARTAN clean-room laboratory at Dalhousie University every 2 months.

Figure 2 shows a diagram of the filter assembly. Each cartridge contains seven pairs of pre-weighed $25 \mathrm{~mm} 2 \mu \mathrm{m}$ poresize PTFE (225-2726, SKC) and capillary membrane (custom grease-coated E8025-MB, SPI) filters sampled actively at $4 \mathrm{~L} \mathrm{~min}^{-1}$ for the programmed period. An eighth cartridge slot contains a travelling blank. An important aspect of this filter assembly design is the automatic switching between filter pairs. Incoming aerosols pass through a bug screen and a greased (ultra-high vacuum) impactor plate, which traps aerosols larger than $10 \mu \mathrm{m}$ in diameter. Coarse-mode $\left(\mathrm{PM}_{\mathrm{c}}\right)$ particles are then removed by a capillary (Nuclepore) membrane $(8 \mu \mathrm{m}$ pore diameter, $5 \%$ porosity). The concept of employing capillary filters for size selection has been well established (Heidam, 1981; John et al., 1983; Parker et al., 1977). This stacked filter unit (SFU) arrangement has similarities with the Gent model (Hopke et al., 1997) and the SFU design has been shown to compare well with other aerosol filter systems (Hitzenberger et al., 2004). The 50\% aerosol capture efficiency is at approximately $2.5 \mu \mathrm{m}$ for the selected flow rate and pore size (Chow, 1995; John et al., 1983). Coarse-mode solid particles are susceptible to particle bounce (John et al., 1983). The manufacturer (SPI) coated the capillary pore membrane surfaces with a thin layer of vacuum grease to enhance their capture efficiency. Fine-mode $\left(\mathrm{PM}_{2.5}\right)$ aerosols are collected on $2 \mu \mathrm{m}$ fibre PTFE filter surfaces, which are compatible with a variety of chemical analyses (Chow, 1995).

\subsubsection{Intermittent air filter sampling procedure}

The SPARTAN sampling procedure is designed to costeffectively measure long-term $\mathrm{PM}_{2.5}$ concentrations. Each filter pair collects for $160 \mathrm{~min}$ each day over a period of 9 days for a total of $24 \mathrm{~h}$ of sampling per filter. To avoid day-of-week biases, 9 day periods have been chosen. Similar duty-cycle sampling protocols have been used in other spatial air monitoring campaigns (Larson et al., 2007). When sampling stops after the 9 day period, the instrument switches to a new filter slot and the next sampling period begins. With seven active filter slots, each cartridge can therefore operate unattended in the field for a 63 day interval. Sampling for new filters on the first day is from 09:00 to 11:40 LT (local time) while the last period runs from 06:20 to 09:00 LT. Appendix A1.3 describes tests, using United States EPA data for hourly-reported $\mathrm{PM}_{2.5}$, in which we find that representativeness errors for annual mean concentrations inferred from staggered sampling as used here are substantially reduced compared to the traditional 1 -in- $x$-days sampling for the same total sample time.

We choose to start sampling runs for each filter in the morning (09:00 LT) when temperatures are lower, to increase retention of temperature-dependent semi-volatile inorganic and organic material that was collected overnight. We tested the behaviour of semi-volatile material (ammonium nitrate) in the cartridge to diurnal heating cycles. Based on our experiments with ammonium nitrate, a moderate loss rate can be expected from the PTFE filters while warm air actively flows over the filters (cf. Appendix A1.2); however, loss rates are minimal during periods when there is no active sampling. Thus we design the sampling protocol to actively sample for only one diurnal cycle and to avoid daytime sampling after nighttime PM has been collected.

Capillary and PTFE filters have a maximum particle loading before a loss of flow is apparent. For locations with higher particulate matter concentrations, we sample between 15 and $100 \%$ of each $2 \mathrm{~h} 40$ min period to prevent filter saturation, as described in Appendix A1.4. Unlike the filter measurements, the collocated nephelometer measures continuously.

\subsubsection{Filter analysis}

All filters are analyzed at Dalhousie University for mass, black carbon, water-soluble ions, and metals. These mea- 
surements provide valuable data to understand and model the $\mathrm{PM}_{2.5} / \mathrm{AOD}$ ratio and for assessing the health effects of aerosols. After air sampling is complete and filter cartridges are returned to Dalhousie University, post-analysis begins with gravimetric filter weighing. Capillary membrane and PTFE filters are equilibrated for $24 \mathrm{~h}$ before weighing on a Sartorius Ultramicro Balance (with a $0.1 \mu \mathrm{g}$ detection limit) in a clean room with controlled temperature $\left(21 \pm 1.5^{\circ} \mathrm{C}\right)$ and humidity $(35 \pm 5 \% \mathrm{RH})$, following EPA protocols (USEPA, 1998). Potential static build-up is eliminated using an electrostatic blower. Absolute mass values are converted to mass concentration of $\mathrm{PM}_{2.5}, \mathrm{PM}_{10}$, and $\mathrm{PM}_{10-2.5}$ by dividing accumulated filter mass by total air

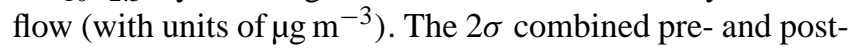
weighing errors average $3.8 \mu \mathrm{g}$, or $0.7 \mu \mathrm{g} \mathrm{m}^{-3}$ for $24 \mathrm{~h}$ of air sampling. This replicate weighing uncertainty corresponds to a precision of $4 \%$ for typical filter loadings of about $100 \mu \mathrm{g}$.

Particle light absorbance of PTFE filters is measured using a Diffusion Systems EEL 43M smoke stain reflectometer (SSR), which acts as a surrogate for black carbon (Quincey et al., 2009). The SSR measurements are calibrated to thermal optical reflectance elemental carbon measurements on prefired quartz filters collected with a collocated Harvard Impactor at each measurement site as recommended in Cyrys et al. (2003). Additional collocated absorption measurements, such as with COSMOS in Beijing (Kondo et al., 2009), are being used for further interpretation.

Filters are then cut in half with a ceramic blade. Soluble ion extraction is performed by sonication on one-half of the filter with $3 \mathrm{~mL}$ of distilled water and $4 \%$ isopropyl alcohol as described by Gibson et al. (2013, 2015). Ionic species (i.e. $\mathrm{F}^{-}, \mathrm{Cl}^{-}, \mathrm{NO}_{2}^{-}, \mathrm{NO}_{3}^{-}, \mathrm{SO}_{4}^{2-}, \mathrm{PO}_{4}^{3-} \mathrm{Li}^{+}, \mathrm{K}^{+}, \mathrm{Na}^{+}, \mathrm{NH}_{4}^{+}$, $\mathrm{Ca}^{2+}$, and $\mathrm{Mg}^{2+}$ ) are separated and quantified by ion chromatography (ICS-1000, Dionex). Major ions species have detection limits of $\sim 10 \mathrm{ng} \mathrm{m}^{-3}$ depending on collected particle masses and potential matrix contaminants.

The other half of the filter is digested in $10 \%$ nitric acid to extract water-insoluble metals (Celo et al., 2010). Trace metals are detected through inductively coupled plasma-mass spectrometry (ICPMS Thermo Scientific X-Series 2). The detection limit for dissolved trace metals depends on the element and sample matrix. For a $3 \mathrm{~mL}$ extraction volume per filter, the 21 detectable metals relevant to atmospheric processes (in $\mathrm{ng} \mathrm{m}^{-3}$, along with the $3 \sigma$ uncertainty) are $\mathrm{Si}(78), \operatorname{Al}(10), \mathrm{Ti}(1), \mathrm{V}(1), \mathrm{Cr}(1), \mathrm{Mn}(2), \mathrm{Fe}(18), \mathrm{Co}(1)$, $\mathrm{Ni}(1), \mathrm{Cu}(2), \mathrm{Zn}(2), \operatorname{As}(1), \operatorname{Se}(3), \operatorname{Ag}(1), \mathrm{Cd}(1), \mathrm{Sn}(2), \mathrm{Sb}(5)$, $\mathrm{Ba}(1), \mathrm{Ce}(1), \mathrm{Pb}(1)$, and $\mathrm{U}(1)$.

\subsection{Nephelometry}

The AirPhoton IN100 nephelometer is a continuous sampling, optically based device measuring total particulate scatter $b_{\mathrm{sp}}$ at red $(632 \mathrm{~nm})$, green $(532 \mathrm{~nm})$, and blue $(450 \mathrm{~nm})$ wavelengths over the angular range 7 to $170^{\circ}$. The AirPhoton nephelometer records backscatter $\left(b_{\mathrm{bks}}\right)$ information be- tween 92 and $170^{\circ}$. Light-emitting diodes supply the light source. Total scatter is related to total aerosol concentration, whereas backscatter provides information on aerosol size distribution. The forward and backscattering measurements are made independently. Correction for angular truncation is in development. Internal sensors measure the incoming air stream for ambient relative humidity, temperature, and pressure. The nephelometer is a separate module from the air sampler and mounts to a support stand. The inlet is a $10 \mathrm{~cm}$ length of copper $1 / 4^{\prime \prime}$ tubing ending with a plastic bug screen. Inlet wall losses for particles below $2.5 \mu \mathrm{m}$ are expected to be less than $2 \%$ (Liu et al., 2011). Light-scatter and backscatter are logged every $15 \mathrm{~s}$ on a 2 GB SD card in units of inverse megametres $\left(\mathrm{Mm}^{-1}\right)$. Ambient air temperature, humidity, and pressure are also recorded at the same frequency on the memory card. The nephelometer is not heated nor is any size cut introduced, and the absence of a dryer also reduces concerns about evaporation of semi-volatile components. The ambient nature of the measured aerosol scatter makes these results consistent with aerosol scatter observed by satellite.

The nephelometer light scattering by particulates, $b_{\mathrm{sp}}$, is reported as $1 \mathrm{~h}$ averages, $b_{\mathrm{sp}, 1 \mathrm{~h}}$. Hourly dry aerosol scatter component, $b_{\mathrm{sp}, \mathrm{dry}-1 \mathrm{~h}}$, is calculated as

$b_{\mathrm{sp}, \mathrm{dry}-1 \mathrm{~h}}=\frac{b_{\mathrm{sp}, 1 \mathrm{~h}}\left\{\mathrm{RH}<\mathrm{RH}_{\max }\right\}}{f_{\mathrm{m}}(\mathrm{RH})}$.

The term $\mathrm{RH}_{\max }$ signifies the exclusion of $b_{\mathrm{sp}}$ values for which the hourly averaged humidity exceeds a threshold, initially taken as $80 \%$, to reduce uncertainty in the effects of aerosol water given the uncertain nature of aerosol composition. The hygroscopic volume correction factor $f_{\mathrm{v}}(\mathrm{RH})$ accounts for the uptake of water in aerosols. We initially use the humidity correction factor $f_{\mathrm{v}}(\mathrm{RH})=1+\kappa \cdot \mathrm{RH} /(100-\mathrm{RH})$. The volume growth factor can often be within experimental error (Kreidenweis et al., 2008) and where the hygroscopicity parameter $\kappa$ depends on aerosol composition. For pure compounds, $\kappa$ is 0 (insoluble and hydrophobic compounds), 0.15 (aged organics), 0.5-0.7 (ammonium sulphate and nitrate), and 1.2 (sea salt) (Hersey et al., 2013; Kreidenweis et al., 2008). Based on our studies in Beijing and the United States, we have found $\kappa=0.2$ represents a variety of aerosol mixtures. This value is similar to that obtained for urban aerosols (Padró et al., 2012). Future work will refine the $f_{\mathrm{v}}(\mathrm{RH})$ calculation for specific site locations via measured composition and its associated hygroscopicity.

\subsection{Merging aerosol filter and nephelometer data}

Hourly nephelometer scatter, as measured by the nephelometer, is approximately proportional to $\mathrm{PM}_{2.5}$ mass (Chow et al., 2006); however, absolute mass predictions depend on aerosol composition. We therefore relate relative fluctuations in dry aerosol scatter from Eq. (1) anchored to an absolute 


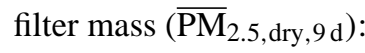

$\mathrm{PM}_{2.5, \mathrm{dry}-1 \mathrm{~h}}=\overline{\mathrm{PM}}_{2.5, \mathrm{dry}, 9 \mathrm{~d}} \frac{b_{\text {sp }, \mathrm{dry}-1 \mathrm{~h}}}{\overline{b_{\text {sp }, \mathrm{dry}, 9 \mathrm{~d}}}}$.

The "dry" subscript refers to the low humidity conditions at which filters are weighed (Sect. 3.2.2). Quantities with bars above them are the 9 day means.

\subsection{Uncertainties and ongoing evaluation}

Measurement uncertainties can be obtained through analyses of blank and replicates. Direct sources of measurement uncertainty are due to absolute $\mathrm{PM}_{2.5}$ weighing $(1 \mu \mathrm{g}$ $\left.\mathrm{m}^{-3}\right)$, nephelometer scatter $\left(1 \mathrm{Mm}^{-1}\right)$, and AOD at visible wavelengths (0.01). We assessed method uncertainties, i.e. the application of Eq. (2), by statistical sub-sampling of data and using federal equivalence method (FEM) instruments for comparison. The method of sampling a filter for $24 \mathrm{~h}$ spread over 9 days introduces a relative uncertainty of $13 \%$ compared with sampling over an entire 9 day interval (cf. Sect. A1.3). Equation (2) was evaluated in a simulated test using $24 \mathrm{~h} \mathrm{PM}_{2.5}$ measurements and nephelometer scatter and compared with hourly tapered element oscillating microbalance (TEOM) $\mathrm{PM}_{2.5}$. The resultant prediction accuracy was $1 \mu \mathrm{g} \mathrm{m}^{-3}+17 \% \times\left[\mathrm{PM}_{2.5}\right]$ at three North American sites and for Beijing (cf. Appendix A1.5). Uncertainties from chemical extractions are listed in Sect. 3.2.2.

The evaluation of the SPARTAN network is an ongoing task. Martins et al. (2015) describe and evaluate the AirPhoton instrumentation in detail. Appendix A2 describes an initial pilot study from university sites in Beijing, Halifax, and Atlanta. Appendix A2.5 describes a Harvard Impactor being circulated across sites for inter-comparison. We have begun a nephelometer and $\mathrm{PM}_{2.5}$ composition intercomparison at Mammoth Cave, Kentucky, between SPARTAN and IMPROVE. Subsequent measurements at the EPA South Dekalb supersite near Atlanta, Georgia, will compare with hourly federal reference method beta attenuation monitor (FRM-BAM) $\mathrm{PM}_{2.5}$ measurements. Comparisons at NOAA and GAW stations would also be instructive. Information gleaned from these assessments is being and will continue to be used to refine instrumentation and protocols.

\section{Initial results}

\subsection{Initial temporal variation of $\mathrm{PM}_{2.5}$ / $\mathrm{AOD}$ in Beijing}

The ratio of ground-level $\mathrm{PM}_{2.5}$ to $\mathrm{AOD}$ is fundamental in inferring $\mathrm{PM}_{2.5}$ from satellite observations of AOD. We introduce initial measurements of this ratio to provide an example of the type of information SPARTAN can provide. The ratio $\eta$, as defined by van Donkelaar et al. (2010), is the ratio of $24 \mathrm{~h} \mathrm{PM} 2.5$ to AOD at satellite overpass time whereas

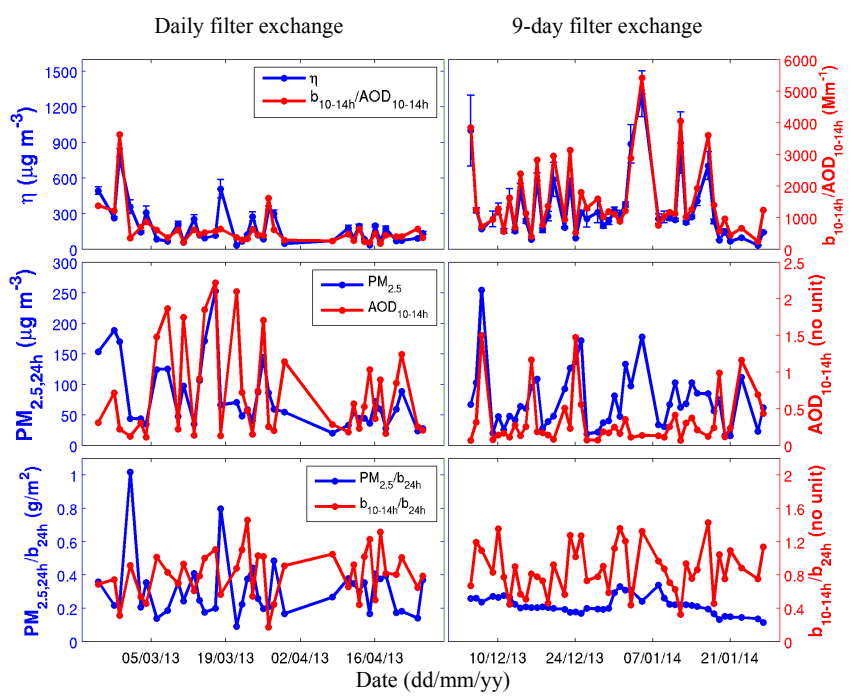

Figure 3. Temporal variation in Beijing, China, of $\eta$ (calculated as the mean $24 \mathrm{~h} \mathrm{PM}_{2.5}$ divided by mean ground-measured AOD retrieved during satellite overpass times) and related variables. Error bars represent $1 \sigma$ measurement uncertainty $\left(\sigma_{\mathrm{PM}_{2.5}}=1 \mu \mathrm{g} \mathrm{m}^{-3}\right.$, $\left.\sigma_{\mathrm{AOD}}=0.02\right)$. The left column (February-April 2013) used daily sampled filters, while the right column (December 2013-January 2014) sampled each filter intermittently over 9 days.

$\mathrm{PM}_{2.5,24 \mathrm{~h}}$ is the daily average of the hourly values obtained in Eq. (2). We define $\mathrm{AOD}_{10-14 \mathrm{~h}}$ as the ground-measured AERONET AOD averaged from 10:00 to 14:00 LT to include a range of common satellite overpass times and interpolated via the Ångström exponents to the wavelength $(550 \mathrm{~nm})$ typically reported for satellite retrievals.

$\eta=\frac{\mathrm{PM}_{2.5,24 \mathrm{~h}}}{\mathrm{AOD}_{10-14 \mathrm{~h}}}$

The top panels of Fig. 3 show daily-varying values of $\eta$ in Beijing, China, for selected months in 2013-2014. Daily $\mathrm{PM}_{2.5}$ ranged from 7 to $228 \mu \mathrm{g} \mathrm{m}^{-3}$ whereas $\mathrm{AOD}_{10-14 \mathrm{~h}}$ ranged from 0.05 to 3.8 during the measured sampling periods (middle panels). We observe that the $\mathrm{PM}_{2.5}$ / $\mathrm{AOD}$ ratio exhibits dramatic daily variation of more than 1 order of magnitude as well, ranging from below $50 \mu \mathrm{g} \mathrm{m}^{-3}$ to above $900 \mu \mathrm{g} \mathrm{m}^{-3}$. We calculated the contribution of $\mathrm{AOD}_{10-14 \mathrm{~h}}$ and $\mathrm{PM}_{2.5,24 \mathrm{~h}}$ to the variation of the dependent variable $\eta$ as the relative contribution to the coefficient of multiple determination $\left(R^{2}\right)$, based on the product of the correlation coefficient $\left(r_{y x(j)}\right)$ and standardized regression coefficients $\left(a_{j}\right)$ for each variable $j$. In Beijing the contributions to $\eta$ of $\mathrm{PM}_{2.5,24 \mathrm{~h}}$ and $1 / \mathrm{AOD}_{10-14 \mathrm{~h}}$ are 0.07 and 0.51 , respectively. The larger contribution from $\mathrm{AOD}_{10-14 \mathrm{~h}}$ indicates the importance of accounting for aerosol aloft. 
We offer further insight into the variation in $\eta$ by decomposing it into three terms:

$\eta=\underbrace{\frac{\left(b_{\mathrm{sp}, 10-14 \mathrm{~h}}\right)}{\mathrm{AOD}_{10-14 \mathrm{~h}}}}_{\mathrm{T} 1} \underbrace{\frac{\left(b_{\mathrm{sp}, 24 \mathrm{~h}}\right)}{b_{\mathrm{sp}, 10-14 \mathrm{~h}}}}_{\mathrm{T} 2} \underbrace{\frac{\left(\mathrm{PM}_{2.5,24 \mathrm{~h}}\right)}{b_{\mathrm{sp}, 24 \mathrm{~h}}}}_{\mathrm{T} 3}$.

Term 1 (T1) is related to height, $H$, for which aerosol scatter would be constant above ground level to obtain the measured AOD and can be thought of as the inverse effective scale height if the total column AOD were distributed vertically according to $b_{\mathrm{sp}}(z) \sim e^{-z / H}$. The second term (T2) accounts for the diurnal variation in near-ground scattering during typical satellite overpass time $\left(b_{\mathrm{sp}, 10-14 \mathrm{~h}}\right)$ versus over the entire $24 \mathrm{~h}$ day $\left(b_{\mathrm{sp}, 24 \mathrm{~h}}\right)$. Term 2 requires only measurements from the nephelometer. The third term (T3) is the inverse of the mass scattering efficiency, which is a function of aerosol size and composition. All nephelometer scatter and AERONET AOD measurements are interpolated to $550 \mathrm{~nm}$ via the nephelometer Ångström exponents to match the wavelengths typically reported for satellite AOD. Hourly scatter values for which RH $>80 \%$ (Eq. 1 ) or $b_{\mathrm{sp}, 532}>1300 \mathrm{Mm}^{-1}$ (nonlinear regime; Appendix A2) are omitted. The product of the three terms in Eq. (4) will cancel to yield Eq. (3).

Figure 3 also shows a time series for these three terms during two sampling intervals. We interpret the time series by determining the contribution of total variance in $\eta$ for Eq. (4) with respect to T1, T2, and T3. Term 1, related to effective scale height, has the largest contribution to the variance in $\eta(0.4)$. Term 2 , related to the diurnal variation in atmospheric scattering, has a smaller, though similar, contribution (0.34). Term 3, related to the mass scattering efficiency, does not contribute significantly to the variance in $\eta$ (contribution $=0.03$ ). Given that hourly $\mathrm{PM}_{2.5}$, as defined in Eq. (2), depends on $b_{\mathrm{sp}}$, we also calculated $\eta_{\mathrm{BAM}}$ as inferred with a second AERONET sun photometer in Beijing and external hourly $\mathrm{PM}_{2.5}$ measurement using a beta attenuation monitor on the roof of the US Embassy, $8 \mathrm{~km}$ southeast of Tsinghua University. The contributions for the three terms to the variance in $\eta$ retain the same essential features, with contributions for $\mathrm{T} 1=0.52$, for $\mathrm{T} 2=0.2$, and for $\mathrm{T} 3 \sim 0$. The majority of the daily variance in $\eta$ in Beijing is therefore explained by the effective scale height of aerosol scattering and more specifically by the relative ground-to-column scattering. Diurnal cycles have some influence on total variance whereas mass scattering efficiency exhibits little influence on the variance in $\eta$. Future work will examine these relationships at other sites, temporally, in detail.

The time periods selected for Fig. 3 represent two separate protocol periods for air filter sampling in Beijing. FebruaryApril 2013 was part of the initial pilot study with filters exchanged every $24 \mathrm{~h}$. The December 2013-January 2014 period was part of the "beta" testing of the 9 day sampling period. It is noteworthy that the relationship of $\eta$ to the three terms in Eq. (4) remains comparable for both time periods despite the extended filter sampling protocol in the latter period.

\subsection{Global variation in $\mathrm{PM}_{2.5}$ / AOD}

We have begun to examine factors affecting the global variation in $\eta$ in order to explore how satellite AOD relates to $\mathrm{PM}_{2.5}$ in different regions of the world. Table 2 contains mean values of $\eta$ and related measurements across SPARTAN sites. Mean $\mathrm{PM}_{2.5}$ concentrations varied from $3.2 \mu \mathrm{g} \mathrm{m}^{-3}$ (Dalhousie) to $102 \mu \mathrm{g} \mathrm{m}^{-3}$ (IIT Kanpur), whereas mean AOD across sites varied from 0.09 (Dalhousie) to 0.8 (Dhaka). Spatial variation of $\eta$ is weaker than spatial variation in $\mathrm{PM}_{2.5}$ or the temporal variation in $\eta$ in Beijing. There is a tendency for $\eta$ to increase with $\mathrm{PM}_{2.5}$; the contribution to the spatial variance in $\eta$ is larger for $\mathrm{PM}_{2.5}$ (contribution $=0.71$ ) than for $\mathrm{AOD}_{10-14 \mathrm{~h}}$ (contribution $=-0.08$ ). We again used Eq. (4) to understand the factors affecting $\eta$. Satellite-coincident ground-level atmospheric scattering AOD ratios contribute significantly to the ratio $\eta$ (T1; contribution $=0.59$ ), as does the mass extinction efficiency (T3; contribution $=0.46$ ); however, the diurnal variation contributes little $(\mathrm{T} 2$; contribution $=-0.22)$. The sub-Saharan site of Ilorin had the lowest values of $\eta$ and the highest $\mathrm{AOD}_{10-14 \mathrm{~h}} / b_{\mathrm{sp}, 10-14 \mathrm{~h}}$ ratio, perhaps reflecting the larger effective aerosol scale height (T1) that may arise from transported dust aloft, and influence from coarse particles, as indicated by a low $\mathrm{PM}_{2.5} / \mathrm{PM}_{\mathrm{c}}$ ratio. We measured the lowest $\mathrm{AOD}_{10-14 \mathrm{~h}} / b_{\mathrm{sp}, 10-14 \mathrm{~h}}$ ratio at the Bandung site, which could be influenced by local volcanic emissions. We found that locations with enhanced $\mathrm{PM}_{2.5}$ generally have lower $\mathrm{AOD}_{10-14 \mathrm{~h}} / b_{\mathrm{sp}, 10-14 \mathrm{~h}}$ ratios (T1), implying lower scale height with a larger fraction of aerosol scattering near the surface. Dhaka, however, had a similar ratio (i.e. only $40 \%$ higher) compared with Halifax as well as similar $\eta$ values (4\% higher) despite 10-fold higher $\mathrm{PM}_{2.5}$ levels, implying a pronounced aerosol scattering layer above Dhaka. Coarse PM also plays a role in Dhaka as apparent from the low $\mathrm{PM}_{2.5} / \mathrm{PM}_{\mathrm{c}}$ ratio. We caution that these results are preliminary, but they demonstrate the potential to understand the relationship between $\mathrm{PM}_{2.5}$ and $\mathrm{AOD}$ at a variety of sites around the world.

Table 2 also contains an initial comparison of the measured values of $\eta$ versus the simulated values from the GEOSChem simulation that van Donkelaar et al. (2010) used to produce global satellite-based $\mathrm{PM}_{2.5}$ estimates. We include in this comparison measurements from the only two locations worldwide (Taiwan and Mexico City) that we found with nearly collocated (within $3 \mathrm{~km}$ ) AOD and $\mathrm{PM}_{2.5}$ measurements. Comparison of mean $\mathrm{PM}_{2.5}$ and AOD reveals that in most locations, measured ratios were within range of GEOSChem estimates, though several are above this range, including in Bandung, Kanpur, Manila, and Halifax. The Bandung site data were well above the GEOS-Chem ratio; however, a volcanic eruption during sampling likely played some role. 
Table 2. Spatial variation in $\eta$ and related variables.

\begin{tabular}{|c|c|c|c|c|c|c|c|c|c|c|c|c|c|}
\hline \multirow{2}{*}{$\begin{array}{l}\text { Host name, } \\
\text { country }\end{array}$} & \multirow[t]{2}{*}{ Time span } & \multicolumn{2}{|c|}{ Site coordinates } & \multirow[t]{2}{*}{$\begin{array}{r}\mathrm{PM}_{2.5,24 \mathrm{~h}} \\
\left(\mu \mathrm{g} \mathrm{m}^{-3}\right)\end{array}$} & \multirow{2}{*}{$\begin{array}{r}\mathrm{AOD}_{10-14 \mathrm{~h}} \\
(550 \mathrm{~nm}) \\
\text { Empirical }\end{array}$} & \multicolumn{2}{|c|}{$\begin{array}{c}\bar{\eta}=\frac{\overline{\mathrm{PM}_{2.5,24 \mathrm{~h}}}}{\overline{\mathrm{AOD}}_{10-14 \mathrm{~h}}} \\
\left(\mu \mathrm{g} \mathrm{m}^{-3}\right)\end{array}$} & \multirow[t]{2}{*}{$\begin{array}{l}\overline{\overline{\mathrm{AOD}_{10-14 \mathrm{~h}}}} \\
\overline{\overline{b_{\mathrm{sp}, 10-14 \mathrm{~h}}}} \\
\left(\mathrm{~T}_{1}^{-1}, \mathrm{~km}\right)\end{array}$} & \multirow[t]{2}{*}{$\begin{array}{l}\frac{\overline{b_{\mathrm{sp}, 10-14 \mathrm{~h}}}}{\overline{b_{\mathrm{sp}, 24 \mathrm{~h}}}} \\
\left(\mathrm{~T}_{2}^{-1}, \%\right)\end{array}$} & \multirow{2}{*}{$\begin{array}{r}\frac{\overline{b_{\text {sp }, 24 \mathrm{~h}}}}{\overline{\mathrm{PM}_{2.5,24 \mathrm{~h}}}} \\
\left(\mathrm{~T}_{3}^{-1}, \mathrm{~m}^{2} \mathrm{~g}^{-1}\right) \\
\text { Empirical }\end{array}$} & \multirow[t]{2}{*}{$\frac{\overline{\mathrm{PM}_{2.5}}}{\overline{\mathrm{PM}_{\mathrm{c}}}}$} & \multirow[t]{2}{*}{$\begin{array}{c}\mathrm{SO}_{4}^{2-} \\
\left(\mu \mathrm{g} \mathrm{m}^{-3}\right)\end{array}$} & \multirow[t]{2}{*}{$\begin{array}{c}\mathrm{NO}_{3}^{2-} \\
\left(\mu \mathrm{g} \mathrm{m}^{-3}\right)\end{array}$} \\
\hline & & Lat & Long & & & & $\begin{array}{l}\text { GEOS- } \\
\text { Chem* }\end{array}$ & & & & & & \\
\hline $\begin{array}{l}\text { Bandung, } \\
\text { Indonesia }\end{array}$ & Jan-Aug 2014 & -6.888 & 107.610 & $37.6 \pm 5.6$ & $0.24 \pm 0.05$ & $124 \pm 4$ & [32-54] & $1.0 \pm 0.04$ & $100 \pm 1$ & $9.8 \pm 0.1$ & 1.57 & 5.5 & 0.4 \\
\hline $\begin{array}{l}\text { Dalhousie } \\
\text { University, Canada }\end{array}$ & Jan-Oct 2013 & 44.638 & -63.594 & $3.2 \pm 0.2$ & $0.09 \pm 0.01$ & $66 \pm 4$ & [25-57] & $3.9 \pm 0.1$ & $62 \pm 2$ & $12.3 \pm 0.6$ & 1.27 & 1.2 & 0.2 \\
\hline $\begin{array}{l}\text { Emory University, } \\
\text { United States }\end{array}$ & $\begin{array}{l}\text { Jan-Mar } \\
2014\end{array}$ & 33.688 & -84.290 & $8.9 \pm 0.6$ & $0.10 \pm 0.01$ & $92 \pm 2$ & [51-104] & $1.7 \pm 0.1$ & $129 \pm 3$ & $5.5 \pm 0.2$ & 1.10 & 1.4 & 0.1 \\
\hline $\begin{array}{l}\text { Ilorin University, } \\
\text { Nigeria }\end{array}$ & Apr-Jun 2014 & 8.481 & 4.526 & $18.5 \pm 1.1$ & $0.74 \pm 0.04$ & $38 \pm 2$ & {$[20-41]$} & $5.2 \pm 0.2$ & $93 \pm 2$ & $8.2 \pm 0.1$ & 0.85 & 1.3 & 0.1 \\
\hline $\begin{array}{l}\text { Indian Institute } \\
\text { of Technology } \\
\text { Kanpur, India }\end{array}$ & $\begin{array}{l}\text { Dec 2013- } \\
\text { May } 2014\end{array}$ & 26.519 & 80.232 & $102 \pm 9$ & $0.51 \pm 0.04$ & $139 \pm 19$ & [61-103] & $2.0 \pm 0.1$ & $87 \pm 1$ & $6.9 \pm 0.1$ & 1.50 & 17.1 & 7.2 \\
\hline $\begin{array}{l}\text { Manila } \\
\text { Observatory, } \\
\text { Philippines }\end{array}$ & Jan-Aug 2014 & 14.635 & 121.077 & $24.7 \pm 0.9$ & $0.27 \pm 0.07$ & $117 \pm 3$ & [35-57] & $1.5 \pm 0.1$ & $92 \pm 1$ & $6.6 \pm 0.1$ & 0.64 & 2.1 & 0.3 \\
\hline Mexico City & Jan-Dec 2013 & 19.333 & -99.182 & $24.4 \pm 0.4$ & $0.27 \pm 0.01$ & $90 \pm 4$ & [79-137] & $\mathrm{n} / \mathrm{a}$ & $\mathrm{n} / \mathrm{a}$ & $\mathrm{n} / \mathrm{a}$ & $\mathrm{n} / \mathrm{a}$ & $\mathrm{n} / \mathrm{a}$ & $\mathrm{n} / \mathrm{a}$ \\
\hline NCU, Taiwan\& & Jan-Dec 2012 & 24.968 & 121.185 & $22.0 \pm 0.3$ & $0.31 \pm 0.02$ & $71 \pm 5$ & [31-73] & $\mathrm{n} / \mathrm{a}$ & $\mathrm{n} / \mathrm{a}$ & $\mathrm{n} / \mathrm{a}$ & $\mathrm{n} / \mathrm{a}$ & $\mathrm{n} / \mathrm{a}$ & $\mathrm{n} / \mathrm{a}$ \\
\hline $\begin{array}{l}\text { Tsinghua } \\
\text { University, China }\end{array}$ & $\begin{array}{l}\text { Feb-Apr } 2013 \\
\text { Nov 2013-Mar } \\
2014\end{array}$ & 39.977 & 116.380 & $86.1 \pm 4.5$ & $0.58 \pm 0.03$ & $141 \pm 5$ & [47-158] & $2.0 \pm<0.1$ & $87 \pm 1$ & $4.6 \pm 0.1$ & 1.01 & 10.5 & 5.1 \\
\hline $\begin{array}{l}\text { University of } \\
\text { Dhaka, Bangladesh }\end{array}$ & $\begin{array}{l}\text { Nov 2013- } \\
\text { May } 2014\end{array}$ & 23.728 & 90.398 & $32.7 \pm 2.9$ & $0.83 \pm 0.04$ & $69^{+} \pm 2$ & [49-73] & $2.8 \pm<0.1$ & $63 \pm 0.3$ & $12.7 \pm 0.5$ & 0.92 & 4.3 & 0.7 \\
\hline
\end{tabular}

Future work will conduct a more rigorous comparison with identical modelled time series.

Additional information from SPARTAN measurements is being prepared for detailed analysis. Already we see that sulfate concentrations varied by more than 1 order of magnitude across sites. Nitrate concentrations in Kanpur and Beijing were 1 order of magnitude higher than elsewhere. Cations offer additional information about sea salt and fine dust. The Ångström exponent and the backscatter fraction measured by the nephelometer offer the prospect of retrieving aerosol size following Kaku et al. (2014).

\subsection{Summary of factors affecting relation of $\mathrm{PM}_{2.5}$ to AOD}

Our initial measurements indicate that the vertical profile of aerosol scattering, which we represent by an effective aerosol scale height, is the most important factor affecting temporal and spatial variation in $\mathrm{PM}_{2.5}$ / AOD. Spatial variation is also strongly affected by the mass scattering efficiency, which implies that efforts to apply satellite AOD to estimate long-term $\mathrm{PM}_{2.5}$ concentrations must be attentive to processes affecting aerosol size and composition. Longer time series from our ongoing measurements will test the robustness of these initial conclusions.

\section{Summary and outlook}

We outlined the development of a grass-roots global network designed to evaluate and enhance satellite-based estimates of fine particulate matter for application in health-effects research and risk assessment. Priority locations were chosen in densely populated areas outside the present reach of North American and European monitoring networks. The network is designed to assess the global heterogeneity between $\mathrm{PM}_{2.5}$ and columnar aerosol optical depth. Data are collected to account for sampling done at specific overpass times and for the frequency of cloud-free conditions. Measurements from existing networks were used to develop and evaluate network design.

The network is comprised initially of two highly autonomous instruments: a three-wavelength nephelometer and an air filter sampler that measures $\mathbf{P M}_{2.5}$ and $\mathbf{P M}_{10}$. The nephelometer reports measurements continuously while the filters report as 9 day averages of particulate dry mass. A key feature of SPARTAN is that sites are collocated with AOD measurements via sun photometer instruments such as through the AERONET network.

The SPARTAN sampling strategy is designed to costeffectively measure long-term and hourly $\mathrm{PM}_{2.5}$ concentrations. Filter cartridges operate autonomously in the field for 2 months, based on this strategy, before requiring replacement with clean cartridges. Each filter cartridge holds eight coarse-mode and eight fine-mode filters with one set as a travelling blank. Each non-blank filter collects PM for one 
diurnal cycle during the course of the sampling period. Sampling ends in the morning when temperatures tend to be low to reduce loss of semivolatiles associated with active warm airflow across filters. $\mathrm{PM}_{2.5}$ is collected on PTFE filters, which are analyzed for total fine particulate mass (gravimetric), black carbon, water-soluble ion speciation (ion chromatography), and metal concentrations (inductively coupled plasma mass spectrometry). All filters are analyzed in one central location under a verified single protocol to ensure similar analysis for filters from all locations. SPARTAN data are being made publicly available along with instrument protocols at spartan-network.org.

An initial analysis of SPARTAN measurements was conducted. We found a pronounced variability of more than 1 order of magnitude in the relation of columnar AOD to groundlevel $\mathrm{PM}_{2.5}$. This variability was analyzed in terms of the factors measured within SPARTAN, including the ratio of ground-level scatter to AOD, the diurnal variation in groundlevel scatter, and the mass scattering efficiency. Data in Beijing indicate that the temporal variation in $\mathrm{PM}_{2.5} / \mathrm{AOD}$ is driven primarily by the vertical profile in aerosol scattering. Spatial variation in $\mathrm{PM}_{2.5}$ across sites ranged from $<10$ to $>100 \mu \mathrm{g} \mathrm{m}^{-3}$. Variation in $\mathrm{PM}_{2.5}$ / AOD between sites is also driven by the aerosol vertical profile and to a lesser extent by the scattering mass efficiency.
Assessment of instrumentation and protocols is an ongoing task. Ongoing work includes (1) further testing of AirPhoton instrumentation at the EPA supersite in Atlanta and at the Mammoth Cave IMPROVE site, (2) the expansion of instrument sites to other sun photometer locations, and (3) implementation of a cyclone $\mathrm{PM}_{2.5}$ inlet to obtain a sharper $\mathrm{PM}_{2.5}$ cut.

Future work will explore utilizing the multi-wavelength capability of the nephelometer to improve $\mathrm{PM}_{2.5}$ estimates by providing refined size distribution information. We are seeking opportunities to expand the instrumentation to create supersites at some SPARTAN locations for related process studies. Collocation with lidar sites would be valuable. The NERC Airborne Science Research and Survey Facility has begun aircraft vertical profiles over four SPARTAN sites (Kanpur, India; Dhaka, Bangladesh; Manila, Philippines; Bandung, Indonesia) SPARTAN is focused on the health applications of all principal measurements. Nonetheless, this network should also provide a unique data set for climate studies and regional $\mathrm{PM}_{2.5}$ source appointment. 

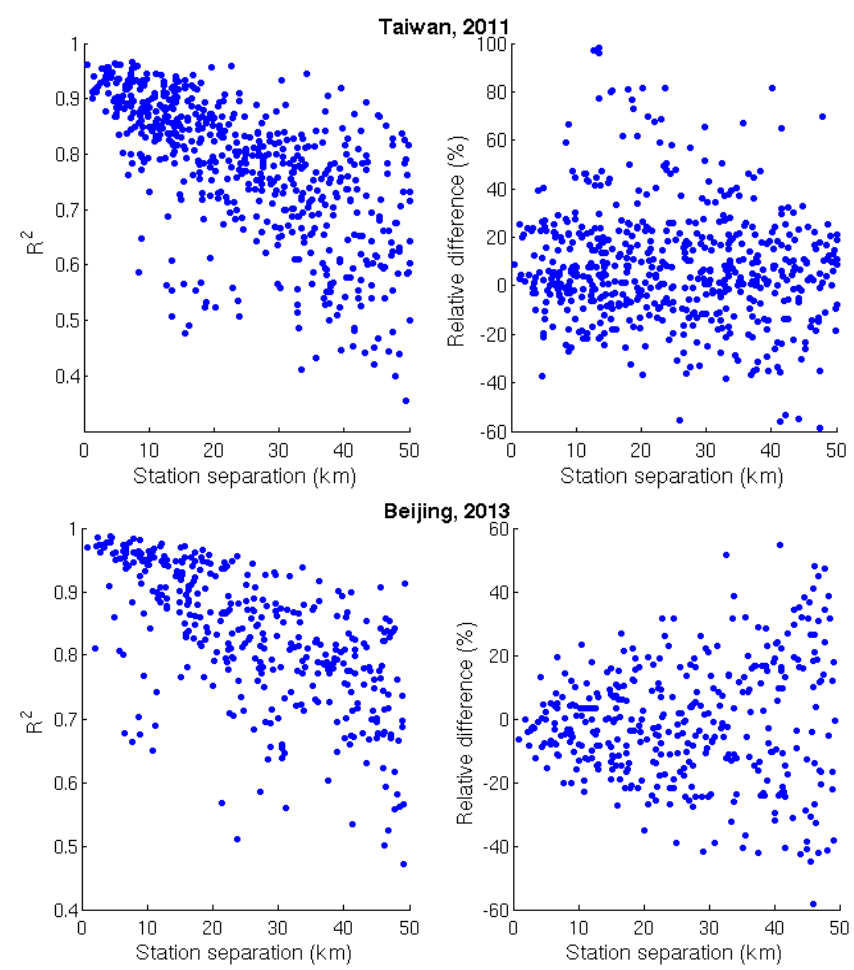

Figure A1. $\mathrm{PM}_{2.5}$ relationships between pairs of stations in Taiwan (calendar year 2011) and Beijing (calendar year 2013). There were 76 stations available in Taiwan for comparison and 36 available in Beijing.

\section{Appendix A: Evaluation of SPARTAN sampling strategy}

\section{A1 Representativeness of a point for an urban area}

We evaluated the degree to which the location of a single aerosol monitoring station is affected by its location within a city by comparing all site pairings (where $n$ sites creates $\left(n^{2}-n\right) / 2$ pairings) for two dense measurement networks in Asia. The left panel in Fig. A1 shows the coefficient of variation $\left(R^{2}\right)$ between daily $\mathrm{PM}_{2.5}$ measured with beta attenuation monitors at 36 sites in Beijing and 76 sites in Taiwan. The coefficient of variation tends towards unity for collocated instruments. Eighty percent of Beijing station pairings separated by less than $10 \mathrm{~km}$ showed $R^{2}>0.90$ while $73 \%$ of Taiwan stations had $R^{2}>0.90$. The right panel is the relative difference (RD) in annual $24 \mathrm{~h}$ mean $\mathrm{PM}_{2.5}$ measured at site pairs $i$ and $j$ such that $\mathrm{RD}_{i j}=2 \cdot\left(\mathrm{PM}_{2.5}^{i}-\right.$ $\left.\mathrm{PM}_{2.5}^{j}\right) /\left(\mathrm{PM}_{2.5}^{i}+\mathrm{PM}_{2.5}^{j}\right)$. The relative errors were symmetric around zero. Station pairings separated by less than $10 \mathrm{~km}$ have mean errors of $12 \%$ in Beijing and $17 \%$ in Taiwan. Single monitoring stations, if properly installed and calibrated, have the potential to represent a satellite observation area on the order of $0.1^{\circ} \times 0.1^{\circ}$. Our analysis of spatial variability is consistent with the $R^{2}>0.8$ found by Anderson et al. (2003) for nephelometer scatter at distances less than $40 \mathrm{~km}$.

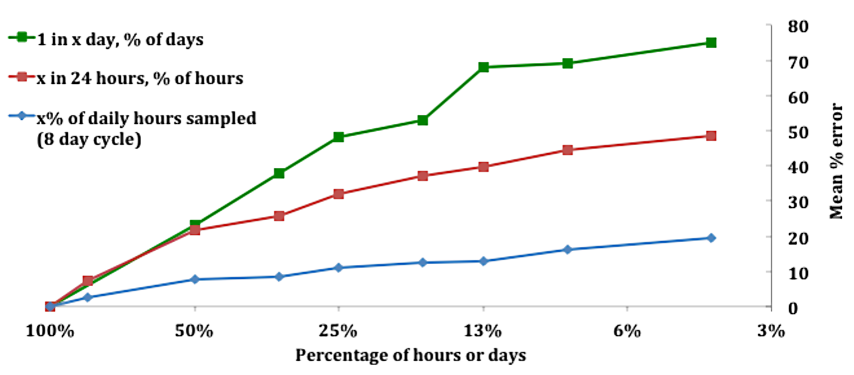

Figure A2. Relative errors representing annual mean $\mathrm{PM}_{2.5}$ obtained from 100 EPA sites averaged over various hourly periods for 2006. Sampling periods are divided into (a) 1 -in- $x$ ( $x=1$ to 24$)$ day sampling intervals (green squares), (b) fraction of day (1 to $24 \mathrm{~h}$ per day, red squares), and (c) staggering $x \%$ of hours per day during an 8 day cycle (blue diamonds).

\section{A2 Losses of aerosol ammonium nitrate}

Ammonium nitrate $\left(\mathrm{NH}_{4} \mathrm{NO}_{3}\right) \mathrm{PM}_{2.5}$ was generated with a mean diameter of $400 \mathrm{~nm}$ using a TSI Constant Output Atomizer (model 3076), then captured on pre-weighed PTFE filters at $23^{\circ} \mathrm{C}$. The mass of captured $\mathrm{NH}_{4} \mathrm{NO}_{3}$ on filters was recorded and filters were returned to the cartridge. The cartridge was then placed in an insulated case held constant at $31^{\circ} \mathrm{C}$. Four filters actively sampled indoor air for $5 \mathrm{~h}$ at $4 \mathrm{~L} \mathrm{~min}^{-1}$ in a heated environment and then were exposed to $15 \mathrm{~h}$ in the heated environment without airflow. Three other filters sat in the heated environment without airflow during this same period. Following this procedure, the mean hourly rate of mass lost from the filters with active airflow was 3.4 $( \pm 0.2) \%$ compared to $0.16( \pm 0.09) \%$ for the filters without active airflow. Moderate loss of $\mathrm{NH}_{4} \mathrm{NO}_{3}$ can be expected from the PTFE filters while warm air is flowing over the filters, but is otherwise slow. Further evidence that ammonium nitrate is retained is that our measured $\mathrm{NO}_{3}^{-} / \mathrm{SO}_{4}^{-}$ratio at Tsinghua of 0.49 (Table 2) is comparable to previous measurements of $0.64( \pm 0.56)$ by Yang et al. (2011) in Beijing.

\section{A3 Assessment of temporal sampling strategy}

We examined how well different sampling approaches represent annual mean $\mathrm{PM}_{2.5}$ concentrations by using hourly measurements of $\mathrm{PM}_{2.5}$ from $\sim 100$ EPA sites across the United States over a year. At each of these locations a beta attenuation monitor or tapered element oscillating microbalance recorded hourly $\mathrm{PM}_{2.5}$ concentrations. We "sampled" these hourly concentrations at intervals of $1,2,3,4,6,8$, 12 , and $24 \mathrm{~h}$ while comparing with uninterrupted sampling. Figure A2 shows the percent error obtained from different sampling approaches.

The green line shows 1 -in- $x$-days sampling errors increase rapidly with decreasing duty cycle. The red line shows that sampling every day at the same time of day has reduced errors compared with 1-in- $x$-days sampling. The blue 
Table A1. Comparison of hourly $\mathrm{PM}_{2.5}$ measured at a site versus predicted using Eq. (1) and a nephelometer at different sites. For all sites a $\mathrm{RH}<80 \%$ cut-off was used to filter humid data.

\begin{tabular}{|c|c|c|c|c|c|c|c|}
\hline $\begin{array}{l}\text { Nephelometer } \\
\text { site }\end{array}$ & $\begin{array}{l}\text { Hourly } \\
\mathrm{PM}_{2.5} \\
\text { site }\end{array}$ & $\begin{array}{r}\text { Distance } \\
\text { between } \\
\text { sites }\end{array}$ & $\begin{array}{r}\# \text { of } \\
\text { obs }\end{array}$ & $\begin{array}{l}\text { Year } \\
\text { span }\end{array}$ & $\begin{array}{r}\text { Mean } \\
24 \mathrm{~h} / \text { midday } \\
\mathrm{PM}_{2.5}\end{array}$ & $\begin{array}{c}24 \mathrm{~h} \text { error, } 1 \sigma_{24 \mathrm{~h}} \\
\left(1 \mu \mathrm{g} \mathrm{m}^{-3}+X \%\right), \\
R^{2}\end{array}$ & $\begin{array}{l}\text { Satellite error, } \sigma_{10-14 \mathrm{~h}} \\
\qquad\left(1 \mu \mathrm{g} \mathrm{m}^{-3}+X \%\right) \\
R^{2}\end{array}$ \\
\hline $\mathrm{MACA}^{\mathrm{a}}$ & $\mathrm{Oak}^{b}$ & $14 \mathrm{~km}$ & 3396 & 2008-2009 & $10.5 / 9.4$ & $16.5 \%, R^{2}=0.87$ & $4.9 \%, R^{2}=0.96$ \\
\hline ROMA $^{\mathrm{a}}$ & Fish $^{\mathrm{b}}$ & $33 \mathrm{~km}$ & 1818 & 2007-2009 & $10.9 / 10.2$ & $15.4 \%, R^{2}=0.51$ & $12.2 \%, R^{2}=0.66$ \\
\hline $\mathrm{NACA}^{\mathrm{a}}$ & Wash $^{b}$ & $3.4 \mathrm{~km}$ & 10302 & 2003-2009 & $10.3 / 9.3$ & $16.6 \%, R^{2}=0.80$ & $10.2 \%, R^{2}=0.89$ \\
\hline Merged & - & - & 14688 & - & $10.4 / 9.4$ & $16.8 \%, R^{2}=0.79$ & $11.7 \%, R^{2}=0.85$ \\
\hline Tsinghua $U$ & US Emb & $8 \mathrm{~km}$ & & 2013 & $141 / 122$ & $17.1 \%, R^{2}=0.88$ & $17.3 \%, R^{2}=0.94$ \\
\hline
\end{tabular}

a IMPROVE Sites (lat, long): MACA (37.037, -86.148), ROMA (32.791, -79.657), NACA (38.900, -77.040). ${ }^{\mathrm{b}}$ EPA Sites (lat, long): Oak (37.037, -86.251), Fish $(32.791,-79.959)$, Wash $(38.922,-77.013)$.

Table A2. Site locations of SPARTAN monitors and the collocated reference instruments for pilot study.

\begin{tabular}{|c|c|c|c|c|c|}
\hline City (university) & Latitude & Longitude & $\begin{array}{r}\text { Reference } \\
\text { light scatter }\end{array}$ & $\begin{array}{l}\text { Reference } \\
\mathrm{PM}_{2.5} \text { filter }\end{array}$ & $\begin{array}{r}\text { Reference } \\
\mathrm{PM}_{\text {coarse }} \text { filter }\end{array}$ \\
\hline & & & DustTrak $^{\mathrm{a}}$, & & \\
\hline Halifax (Dalhousie) & $+44.638^{\circ}$ & $-63.594^{\circ}$ & Dylos $^{\mathrm{b}}$, Aurora $^{\mathrm{c}}$ & Partisol $^{\mathrm{e}}, \mathrm{BAM}^{\mathrm{f}}$ & Partisol $^{\mathrm{e}}$ \\
\hline Atlanta (Emory) & $+33.798^{\circ}$ & $-84.323^{\circ}$ & GRIMM $^{\mathrm{d}}$ & PEM $^{\mathrm{g}}$ & None \\
\hline Beijing (Tsinghua) & $+39.997^{\circ}$ & $+116.329^{\circ}$ & DustTrak $^{\mathrm{a}}$ & $\begin{array}{r}\text { BAM }^{\mathrm{f}}, \text { Laoying }^{\mathrm{i}} \\
\text { TEOM }^{\mathrm{h}},\end{array}$ & None \\
\hline
\end{tabular}

\footnotetext{
${ }^{\text {a }}$ DustTrak model 8533 in Halifax, model 8530 in Beijing (TSI); ${ }^{\mathrm{b}}$ Dylos DC1700 (Dylos); ${ }^{\mathrm{c}}$ Aurora 3000 (Ecotech); ${ }^{\mathrm{d}}$ GRIMM model 1.109 (GRIMM); ${ }^{\mathrm{e}}$ Partisol 2025 (Thermo Scientific); ${ }^{\mathrm{f}}$ beta attenuation monitor 1020 (Met One); ${ }^{\mathrm{g}}$ personal environmental monitor model 761-203B (PEM); ${ }^{\mathrm{h}}$ tapered element oscillating microbalance series $1400 \mathrm{a}$ with a $50^{\circ} \mathrm{C}$ sample stream (Thermo Scientific); ${ }^{\mathrm{i}}$ Laoying model 2030 using $90 \mathrm{~mm}$ PTFE filters.
}
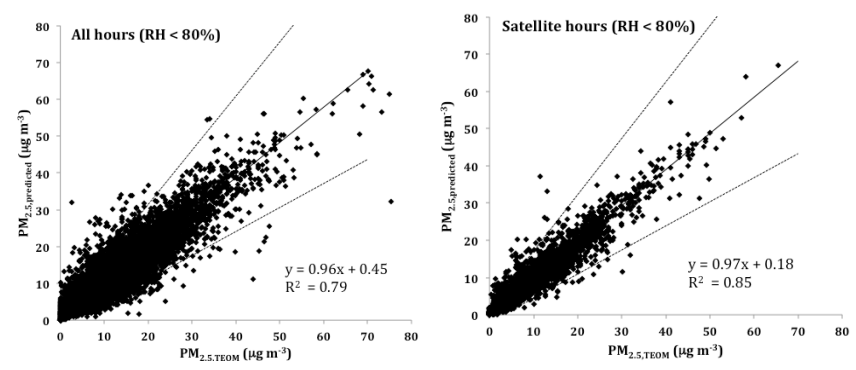

Figure A3. Comparison of predicted hourly fine mass versus measured TEOM PM 2.5 for combined NACA, ROMA, and MACA sites (for $\mathrm{RH}<80 \%$ ). Dashed lines show $2 \sigma$ confidence interval for predicted $\mathrm{PM}_{2.5}$ RMA slope.

line shows staggered sampling. A $3 \mathrm{~h}$ interval (12.5\% sampling) means day one samples from 00:00 to 03:00 LT, day two samples from 03:00 to 06:00 LT, etc., until day eight is reached. Shorter sampling intervals require more days to reach a $24 \mathrm{~h}$ average. Staggered sampling reduced representativeness errors compared with single-day sampling. Sampling error increases slowly as duty cycle decreases. The red line shows that sampling $3 \mathrm{~h}$ at the same time each day results in a $40 \%$ daily mean error; however, the expected error for $3 \mathrm{~h}$ staggered intervals over an 8 day mean was much lower at $13 \%$. Thus we choose staggered sampling to increase the representativeness of mean $\mathrm{PM}_{2.5}$ measurements.

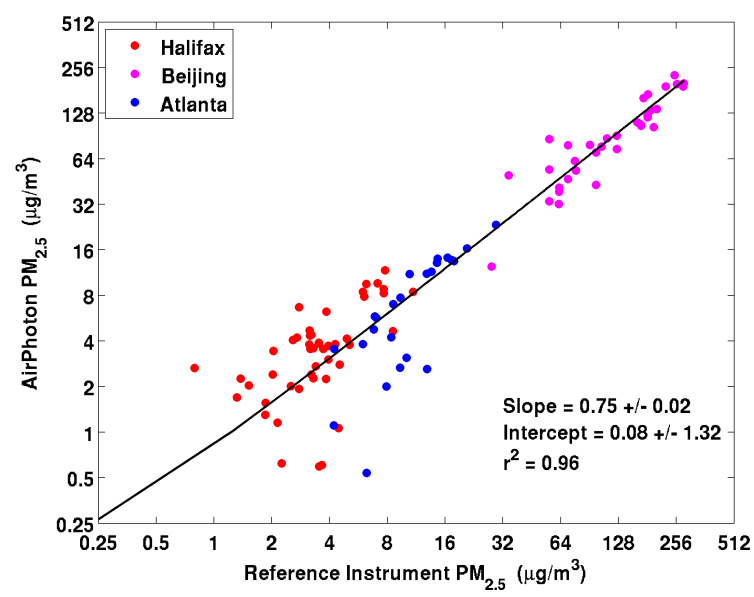

Figure A4. Scatter plot shows reduced major axis (RMA) regression for Beijing, Atlanta, and Halifax $\mathrm{PM}_{2.5}$ concentrations. AirPhoton filter samplers in Halifax, Atlanta, and Beijing were referenced using Partisol, PEM, and Laoying air sampler instruments, respectively.

\section{A4 Modifying protocol for high $\mathbf{P M}_{2.5}$ concentrations}

Six consecutive 9 day tests at the Atlanta site measured the loss of airflow through the AirPhoton instrument. Initially, filters collected aerosols without any change in flow; however, a $10 \%$ loss of airflow became apparent when more 
than $160 \mu \mathrm{g}$ of coarse aerosol material deposited on the capillary pore surface (i.e. $50 \mu \mathrm{g} \mathrm{cm}^{-2}$ ). Given a flow rate of $4 \mathrm{~L} \mathrm{~min}^{-1}$, this is equivalent to a maximum sustainable PM concentration of $28 \mu \mathrm{g} \mathrm{m}^{-3}$. We avoid exceeding a median threshold of half this value; sites with ambient $\mathrm{PM}_{\mathrm{c}}$ concentrations less than $14 \mu \mathrm{g} \mathrm{m}^{-3}$ are sampled for $160 \mathrm{~min}$ a day over 9 days (i.e. $24 \mathrm{~h}$ total; $100 \%$ duty). Elsewhere, the daily sampling duration (\% duty) follows Eq. (A1) to avoid collecting more than $160 \mu \mathrm{g}$ of $\mathrm{PM}_{\text {coarse }}$.

$$
\% \text { Duty } \approx\left\{\begin{array}{c}
100 \% \overline{\mathrm{PM}_{\mathrm{c}}} \leq 14 \mu \mathrm{g} \mathrm{m}^{-3} \\
\frac{160 \mu \mathrm{g}}{2\left[\overline{\mathrm{PM}_{\mathrm{c}}}\right] \cdot V_{\mathrm{samp}}} \cdot 100 \% \overline{\mathrm{PM}_{\mathrm{c}}}>14 \mu \mathrm{g} \mathrm{m}^{-3}
\end{array}\right.
$$

$V_{\text {samp }}$ is the volume of air passing through the filter in $24 \mathrm{~h}\left(5.76 \mathrm{~m}^{3}\right.$ for $24 \mathrm{~h}$ at $\left.4 \mathrm{~L} \mathrm{~min}^{-1}\right)$. Initial $\overline{\mathrm{PM}_{\mathrm{c}}}$ concentrations are estimated from available data. When coarse-mode ground-level aerosol is unknown, a doubling of satellitederived $\mathrm{PM}_{2.5}$ is used in Eq. (A1) as an initial estimate. Actual duty cycles are being refined as more SPARTAN data are acquired.

\section{A5 Expected daily $\mathbf{P M}_{2.5}$ errors during satellite observation times}

We examined the quality of hourly $\mathrm{PM}_{2.5}$ inferred from Eq. (1) for $24 \mathrm{~h}$ periods and during typical satellite daytime observation times (10:00 to 14:00). This test case was based on three IMPROVE network sites near EPA sites. The IMPROVE sites provide hourly nephelometer $\left(b_{\mathrm{sp}}\right)$ readings while EPA sites provided hourly $\mathrm{PM}_{2.5}$ mass using a TEOM instrument. We discarded all $b_{\mathrm{sp}}$ values for which hourly $\mathrm{RH}>80 \%$. We identified three EPA and IMPROVE sites that were (a) within $50 \mathrm{~km}$ of each other, (b) had less than a $100 \mathrm{~m}$ elevation difference, and (c) had at least 1 year of sampling overlap. We compared $\mathrm{PM}_{2.5}$ predictions versus hourly TEOM for both satellite and $24 \mathrm{~h}$ averages and attempted to account for aerosol water using Eq. (1). Uniquely for this analysis, we defined $\overline{\mathrm{PM}}_{2.5 \text {, dry }}$ in Eq. (2) as a $24 \mathrm{~h}$ average of the TEOM. By substituting gravimetric masses for this average we isolated the error contribution from Eq. (1) and ignored inter-instrument bias. TEOM and BAM instruments have inherent hourly $1 \sigma$ precisions of $2 \mu \mathrm{g} \mathrm{m}^{-3}$ and daily precisions of $1 \mu \mathrm{g} \mathrm{m}^{-3}$ (Thermo Scientific, 2013). An offset of $1 \mu \mathrm{g} \mathrm{m}^{-3}$ was used to account for instrument uncertainties.

Figure A3 gives the results from all three EPA/IMPROVEpaired locations. The slope is near unity for both all-day and satellite hours $\left(m_{24 \mathrm{~h}}=0.96, m_{10-14 \mathrm{~h}}=0.97\right)$. The mean $24 \mathrm{~h}$ error is $16.8 \%$. Some errors are due to EPA and IMPROVE sites not being collocated. Uncertainties in aerosol water also contribute to error. We find increasing relative errors if we introduce higher $\mathrm{RH}$ cutoffs; increasing the $\mathrm{RH}$ cutoff from 80 to $90 \%$ using IMPROVE data increases error by $10-20 \%$.

Table A1 includes the errors obtained from the three US locations. Moving from $24 \mathrm{~h}$ to satellite overpass times reduces average all-day errors from $1 \mathrm{\mu g} \mathrm{m}^{-3}+17 \%(24 \mathrm{~h})$ to
$1 \mu \mathrm{g} \mathrm{m}^{-3}+12 \%$ for satellite overpass hours. Midday hours have lower relative humidity.

\section{Appendix B: Pilot project air sampling and weighing protocol}

\section{B1 Test sites and collocated instruments}

Three test sites were chosen to represent locations of high $\mathrm{PM}_{2.5}$ (Tsinghua University; Beijing, China), moderate $\mathrm{PM}_{2.5}$ (Emory University; Atlanta, USA) and low $\mathrm{PM}_{2.5}$ (Dalhousie University; Halifax, Canada) concentrations. For each site the AirPhoton air sampler and nephelometer were collocated with at least one filter-based and light-scattering instrument. Halifax had two federal reference method (FRM) instruments on site: the Partisol 2025 (PM 2.5 of EQPS-0509179, PM $_{\text {coarse }}$ of EQPS-0509-180; Themo Scientific) and the BAM (EQPM-0308-170; Met One). Beijing had one FRM on site: the TEOM 1400 (EQPM-0609-181). We compare with BAM data as reported from the US Embassy (twitter.com/beijingair) located $8 \mathrm{~km}$ southeast of Tsinghua University. Table A2 contains a full listing of intercomparison instruments.

\section{B2 Nephelometer trending}

The AirPhoton nephelometer was collocated with several other nephelometer instruments: the DustTrak, Aurora, and Dylos instruments in Halifax, a GRIMM monitor in Atlanta, and DustTrak instrument in Beijing. All instruments sampled at ambient conditions without size cut or drying. Measurements with $\mathrm{RH}>80 \%$ were excluded. Good correlation ( $R^{2}=0.80$ to 0.98 ) was found for all three sites at red, green, and blue wavelengths compared to 5 to $15 \mathrm{~min}$ averages of reference instruments.

In Beijing the prototype AirPhoton nephelometer signal saturated during extreme low-humidity pollution events $\left(\mathrm{PM}_{2.5}>400 \mu \mathrm{g} \mathrm{m}^{-3}\right)$ such that $b_{\mathrm{sp}}>1300 \mathrm{Mm}^{-1}$, and these data were omitted from averages. Light scattering performance returned to normal after these events. The Beijing pollution episodes from January to March 2013 were exceptional but modifications to the nephelometer to accommodate up to $2000 \mathrm{Mm}^{-1}$ dry aerosol scattering have been implemented to accommodate these extreme cases.

\section{B3 Assembled $\mathbf{P M}_{2.5}$ filter results from all three cities}

Figure A4 illustrates the $\mathrm{PM}_{2.5}$ masses as obtained by filter weight from the three cities Halifax, Atlanta, and Beijing. Each site used a different reference instrument. For the purpose of estimating global $\mathrm{PM}_{2.5}$, there is some precedent for combining data from various reference sources (Brauer et al., 2011). After merging our data sets from all three cities, the resulting coefficient of variation is 0.96 . The combined slope is $0.75 \pm 0.02$ with a negligibly small intercept 
of $-0.08 \mu \mathrm{g} \mathrm{m}^{-3}$. These differences are similar to previous comparisons between approved FRM and FEM instruments (Cyrys et al., 2001; Hains et al., 2007; Liu et al., 2013; Motallebi et al., 2003; Schwab et al., 2006). Nonetheless, the low slope implies that the AirPhoton prototype underestimated $\mathrm{PM}_{2.5}$ with respect to reference instruments. The $\mathrm{Nu}$ clepore filters provide only an approximate $\mathrm{PM}_{2.5}$ size cut. At each SPARTAN site a Harvard Impactor is used to assess the location-specific effects of the size cut until a $\mathrm{PM}_{2.5} \mathrm{cy}-$ clone inlet becomes available for AirPhoton instruments.

In Halifax, the slope of the AirPhoton $\mathrm{PM}_{2.5}$ estimates with respect to the Partisol was $1.26 \pm 0.12$. The moderate correlation $\left(R^{2}=0.55\right)$ is likely due to the low mean $\mathrm{PM}_{2.5}$ concentrations $\left(4.4 \mu \mathrm{g} \mathrm{m}^{-3}\right)$ over the January-March sampling period. These concentrations are at the low end of annual averages recorded for any populated area in the world (Brauer et al., 2011). The Halifax AirPhoton site underreported $\mathrm{PM}_{\text {coarse }}$ with respect to Partisol, at $0.74 \pm 0.06$ $\left(R^{2}=0.70\right)$. In Atlanta the slope of $\mathrm{PM}_{2.5}$ was $0.88 \pm 0.08$ with respect to a personal environmental monitor (PEM) reference filter. The $R^{2}$ of the two data sets is 0.82 .

The Beijing air samples followed a reduced sampling protocol. The city of Beijing experienced very high levels of $\mathrm{PM}_{2.5}$ during this pilot study, with hourly concentrations passing $500 \mathrm{\mu g} \mathrm{m}^{-3}$ and daylong averages occasionally above $200 \mu \mathrm{g} \mathrm{m}^{-3}$. Sampling was decreased to $10 \%$ of every hour (for a total of $2.4 \mathrm{~h}$ per day) to avoid filter clogging. The reported $\mathrm{PM}_{2.5}$ values correlated well $\left(R^{2}=0.87\right)$ with the Laoying. The slope is low compared with the Laoying (0.77) and the BAM (0.64) but close to the TEOM (0.93); the latter is known to underreport $\mathrm{PM}_{2.5}$ due to semivolatile losses (Cyrys et al., 2001).

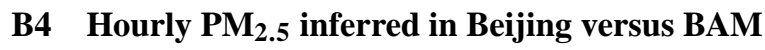 instrument}

Figure A5 shows hourly $\mathrm{PM}_{2.5}$ at Tsinghua University between 23 February and 29 March 2013. Daily PM $_{2.5}$ concentrations are defined as $24 \mathrm{~h}$ averages reported by the BAM, [ERR:md:MbegChr=0x2329, MendChr=0x232A, $\mathrm{nParams}=1]_{\mathrm{BAM}}$, to eliminate sources of error dependent on dry mass calculations. Green nephelometer $(532 \mathrm{~nm})$ total scatter values and humidity were used to infer hourly $\mathrm{PM}_{2.5}$ estimates using Eq. (1). These values were normalized every $24 \mathrm{~h}$ (excluding those hours for which humidity is above $80 \%$ ) and compared with the hourly BAM data. We focused on the predictive ability of the nephelometer for hourly $\mathrm{PM}_{2.5}$. Green $(532 \mathrm{~nm})$ scatter above $1300 \mathrm{Mm}^{-1}$ was screened as higher aerosol concentrations were nonlinear. Promising correlations are found with $24 \mathrm{~h}$ BAM fine mass $\left(R_{24 \mathrm{~h} \text {,hourly }}^{2}=0.88\right)$ and satellite overpass times averages $\left(R_{10-14 \mathrm{~h} \text {,hourly }}^{2}=0.94\right)$ despite the $8 \mathrm{~km}$ of separation between the BAM and nephelometer. The lower correlation of the all-day relationship is likely due to slight non-linearities for $\mathrm{PM}_{2.5}$ concentrations above $400 \mu \mathrm{g} \mathrm{m}^{-3}$.
The standard deviation $(1 \sigma)$ envelope compared with the reduced major axis (e.g. Gibson et al., 2009) line for BAMreferenced $\mathrm{PM}_{2.5}$ is $1 \mu \mathrm{g} \mathrm{m}^{-3}+17 \%$ for both all-day and satellite-only values. Mass differences for the Beijing pilot test were comparable to the multi-year trial estimates in the United States (Table A1). A sensitivity test that extended the reference period to $24 \mathrm{~h} \mathrm{PM}_{2.5}$ means (with scatter and $\mathrm{PM}_{2.5}$ averaged over 9 day spans) resulted in similar $\mathrm{PM}_{2.5}$ discrepancies, at $1 \mu \mathrm{g} \mathrm{m}^{-3}+16 \%$, but with reduced variance $\left(R_{24 \mathrm{~h} \text {, daily }}^{2}=0.94\right)$.

\section{B5 Additional measurements}

A Harvard Impactor is used to assess the performance of size cut of AirPhoton instruments for the conditions at their sampling locations until a $\mathrm{PM}_{2.5}$ cyclone inlet becomes available for the AirPhoton sampling station. These instruments are straightforward to operate and pre-programmed sampling pump protocols are provided. Harvard Impactors are known to provide an accurate measurement of $\mathrm{PM}_{2.5}$ (Babich et al., 2000), and two are being shipped to each site for 3 weeks of daily collocated sampling. The AirPhoton instrument operates on a daily cycle for expediency during this intercalibration period. Further assessment to account for different seasons will be conducted using the cyclone inlet. After sampling, the PTFE and quartz filters are returned to Dalhousie University for analysis. PTFE filters are post-weighed and quartz filters are analyzed for elemental carbon via an OC/EC analyzer (Sunset Laboratory). The EC mass fraction is used to assess the $\mathrm{BC}$ inferred with the smoke stain reflectometer instrument. 
Acknowledgements. The National Sciences and Engineering Research Council (NSERC) of Canada supported this work. We are grateful to many others who have offered helpful comments and advice on the creation of this network including Jay Al-Saadi, Ross Anderson, Kalpana Balakrishnan, Len Barrie, Sundar Christopher, Matthew Cooper, Jim Crawford, Doug Dockery, Jill Engel-Cox, Greg Evans, Markus Fiebig, Allan Goldstein, Judy Guernsey, Ray Hoff, Rudy Husar, Mike Jerrett, Michaela Kendall, Rich Kleidman, Petros Koutrakis, Glynis Lough, Doreen Neil, John Ogren, Norm O'Neil, Jeff Pierce, Thomas Holzer-Popp, Ana Prados, Lorraine Remer, Sylvia Richardson, and Frank Speizer. We would like to thank Elliott Wright and Heather Daurie at the Dalhousie CWRS facility for their help with ICP-MS analysis. The site at IIT Kanpur is supported in part by the National Academy of Sciences and USAID; however, the views expressed here are of the authors and do not necessarily reflect those of the NAS or USAID.

Edited by: F. Boersma

\section{References}

Anderson, T. L., Charlson, R. J., Winker, D. M., Ogren, J. A., and Holmén, K.: Mesoscale Variations of Tropospheric Aerosols, J. Atmos. Sci., 60, 119-136, doi:10.1175/15200469(2003)060<0119:MVOTA>2.0.CO;2, 2003.

Anenberg, S. C., Horowitz, L. W., Tong, D. Q., and West, J. J.: An estimate of the global burden of anthropogenic ozone and fine particulate matter on premature human mortality using atmospheric modeling, Environ. Health Perspect., 118, 1189-1195, 2010

Babich, P., Davey, M., Allen, G., and Koutrakis, P.: Method Comparisons for Particulate Nitrate, Elemental Carbon, and PM2.5 Mass in Seven U.S. Cities, J. Air Waste Manage. Assoc., 50, 1095-1105, doi:10.1080/10473289.2000.10464152, 2000.

Bell, M. L., Morgenstern, R. D., and Harrington, W.: Quantifying the human health benefits of air pollution policies: Review of recent studies and new directions in accountability research, Environ. Sci. Policy, 14, 357-368, doi:10.1016/j.envsci.2011.02.006, 2011.

Brauer, M., Amann, M., Burnett, R. T., Cohen, A., Dentener, F., Ezzati, M., Henderson, S. B., Krzyzanowski, M., Martin, R. V, Van Dingenen, R., van Donkelaar, A., and Thurston, G. D.: Exposure Assessment for Estimation of the Global Burden of Disease Attributable to Outdoor Air Pollution, Environ. Sci. Technol., 46, 652-660, doi:10.1021/es2025752, 2011.

Celo, V., Dabek-Zlotorzynska, E., Mathieu, D., and Okonskaia, I.: Validation of a Simple Microwave-Assisted Acid Digestion Method Using Microvessels for Analysis of Trace Elements in Atmospheric PM2.5 in Monitoring and Fingerprinting Studies, Open Chem. Biomed. J., 3, 143-152, doi:10.2174/1875038901003010143, 2010.

Chen, H., Goldberg, M. S., and Villeneuve, P. J.: A systematic review of the relation between long-term exposure to ambient air pollution and chronic diseases., Rev. Environ. Health, 23, 243 297, 2008

Chow, J. C.: Measurement Methods to Determine Compliance with Ambient Air Quality Standards for Suspended
Particles, J. Air Waste Manage. Assoc., 45, 320-382, doi:10.1080/10473289.1995.10467369, 1995.

Chow, J. C., Watson, J. G., Park, K., Lowenthal, D. H., Robinson, N. F., and Magliano, K. A.: Comparison of particle light scattering and fine particulate matter mass in central California., J. Air Waste Manage. Assoc., 56, 398-410, 2006.

Crouse, D. L., Peters, P. A., Donkelaar, A. van, Goldberg, M. S., Villeneuve, P. J., Bnon, O., Than, S., Afari, D. O., Jerrett, M., Pope, C. A., Brauer, M., Brook, J. R., Martin, R. V., Steib, D., and Burnett, R. T.: Risk of Nonaccidental and Cardiovascular Mortality in Relation to Long-term Exposure to Low Concentrations of Fine Particulate Matter: A Canadian National-Level Cohort Study, Environ. Health Perspect., 120, 708-714, 2012.

Cyrys, J., Dietrich, G., Kreyling, W., Tuch, T., and Heinrich, J.: $\mathrm{PM}_{2.5}$ measurements in ambient aerosol: comparison between Harvard impactor $(\mathrm{HI})$ and the tapered element oscillating microbalance (TEOM) system, Sci. Total Environ., 278, 191-197, doi:10.1016/S0048-9697(01)00648-9, 2001.

Cyrys, J., Heinrich, J., Hoek, G., Meliefste, K., Lewne, M., Gehring, U., Bellander, T., Fischer, P., Vliet, P. van, Brauer, M., Wichmann, H.-E., and Brunekreef, B.: Comparison between different traffic-related particle indicators: Elemental carbon (EC), PM2.5 mass, and absorbance, J. Expo Anal. Env. Epidemiol, 13, 134143, 2003.

Fang, Y., Mauzerall, D., Liu, J., Fiore, A., and Horowitz, L.: Impacts of 21 st century climate change on global air pollutionrelated premature mortality, Clim. Change, 121, 239-253, doi:10.1007/s10584-013-0847-8, 2013.

Friedl, L., Husar, R., and Falke, S.: GEO Task US-09-01a: Critical Earth Observations Priorities, Washington, 2010.

Gibson, M. D., Guernsey, J. R., Beauchamp, S., Waugh, D., Heal, M. R., Brook, J. R., Maher, R., Gagnon, G. A., McPherson, J P., Bryden, B., Gould, R., and Terashima, M.: Quantifying the spatial and temporal variation of ground-level ozone in the rural Annapolis Valley, Nova Scotia, Canada using nitrite-impregnated passive samplers, J. Air Waste Manag. Assoc., 59, 310-320, 2009.

Gibson, M. D., Haelssig, J., Pierce, J. R., Parrington, M., Franklin, J. E., Hopper, J. T., Li, Z., and Ward, T. J.: A comparison of four receptor models used to quantify the boreal wildfire smoke contribution to surface $\mathrm{PM}_{2.5}$ in Halifax, Nova Scotia during the BORTAS-B experiment, Atmos. Chem. Phys., 15, 815-827, doi:10.5194/acp-15-815-2015, 2015.

Gibson, M. D., Heal, M. R., Li, Z., Kuchta, J., King, G. H., Hayes, A., and Lambert, S.: The spatial and seasonal variation of nitrogen dioxide and sulfur dioxide in Cape Breton Highlands National Park, Canada, and the association with lichen abundance, Atmos. Environ., 64, 303-311, doi:10.1016/j.atmosenv.2012.09.068, 2013.

GPWv3: Gridded Population of the World: Population Density Grid, Future Estimates, Cent. Int. Earth Sci. Inf. Netw. - CIESIN - Columbia Univ. Cent. Int. Agric. Trop. CIAT. 2010, available at: http://sedac.ciesin.columbia.edu/data/ set/gpw-v3-population-density (last access: 7 November 2013), 2005.

Hains, J. C., Chen, L.-W. A., Taubman, B. F., Doddridge, B. G., and Dickerson, R. R.: A side-by-side comparison of filter-based PM2.5 measurements at a suburban site: A closure study, Atmos. 
Environ., 41, 6167-6184, doi:10.1016/j.atmosenv.2007.04.008, 2007.

Hand, J. L., Schichtel, B. A., Pitchford, M., Malm, W. C., and Frank, N. H.: Seasonal composition of remote and urban fine particulate matter in the United States, J. Geophys. Res., 117, D05209, doi:10.1029/2011JD017122, 2012.

HEI: Outdoor Air Pollution and Health in the Developing Countries of Asia: A Comprehensive Review, Special Report 18, Boston, MA, 2010.

Heidam, N. Z.: Review: Aerosol fractionation by sequential filtration with nuclepore filters, Atmos. Environ., 15, 891-904, doi:10.1016/0004-6981(81)90088-3, 1981.

Hersey, S. P., Craven, J. S., Metcalf, A. R., Lin, J., Lathem, T., Suski, K. J., Cahill, J. F., Duong, H. T., Sorooshian, A., Jonsson, H. H., Shiraiwa, M., Zuend, A., Nenes, A., Prather, K. A., Flagan, R. C., and Seinfeld, J. H.: Composition and hygroscopicity of the Los Angeles Aerosol: CalNex, J. Geophys. Res.-Atmos., 118, 30163036, doi:10.1002/jgrd.50307, 2013.

Hitzenberger, R., Berner, A., Galambos, Z., Maenhaut, W., Cafmeyer, J., Schwarz, J., Müller, K., Spindler, G., Wieprecht, W., Acker, K., Hillamo, R., and Mäkelä, T.: Intercomparison of methods to measure the mass concentration of the atmospheric aerosol during INTERCOMP2000 - influence of instrumentation and size cuts, Atmos. Environ., 38, 6467-6476, doi:10.1016/j.atmosenv.2004.08.025, 2004.

Hoff, R. M. and Christopher, S. A.: Remote Sensing of Particulate Pollution from Space: Have We Reached the Promised Land?, J. Air Waste Manage. Assoc., 59, 645-675, 2009.

Holben, B. N., Eck, T. F., Slutsker, I., Tanré, D., Buis, J. P., Setzer, A., Vermote, E., Reagan, J. A., Kaufman, Y. J., Nakajima, T., Lavenu, F., Jankowiak, I., and Smirnov, A.: AERONET - A Federated Instrument Network and Data Archive for Aerosol Characterization, Remote Sens. Environ., 66, 1-16, doi:10.1016/S0034-4257(98)00031-5, 1998.

Hopke, P. K., Xie, Y., Raunemaa, T., Biegalski, S., Landsberger, S., Maenhaut, W., Artaxo, P., and Cohen, D.: Characterization of the Gent Stacked Filter Unit PM10 Sampler, Aerosol Sci. Technol., 27, 726-735, doi:10.1080/02786829708965507, 1997.

Husar, R. B., Husar, J. D., and Martin, L.: Distribution of continental surface aerosol extinction based on visual range data, Atmos. Environ., 34, 5067-5078, doi:10.1016/S1352-2310(00)00324-1, 2000.

John, W., Hering, S., Reischl, G., Sasaki, G., and Goren, S.: Characteristics of Nuclepore filters with large pore size - II. Filtration properties, Atmos. Environ., 17, 373-382, doi:10.1016/00046981(83)90054-9, 1983.

Kahn, R. A., Ogren, J. A., Ackerman, T. P., Bosenberg, J., Charlson, R. J., Diner, D. J., Holben, B. N., Menzies, R. T., Millier, M. A., and Seinfeld, J. H.: Aerosol Data Sources and Their Roles within PARAGON, B. Am. Meteorol. Soc., 85, 1511-1522, 2004.

Kaku, K. C., Reid, J. S., O’Neill, N. T., Quinn, P. K., Coffman, D. J., and Eck, T. F.: Verification and application of the extended spectral deconvolution algorithm (SDA+) methodology to estimate aerosol fine and coarse mode extinction coefficients in the marine boundary layer, Atmos. Meas. Tech., 7, 3399-3412, doi:10.5194/amt-7-3399-2014, 2014.

Kondo, Y., Sahu, L., Kuwata, M., Miyazaki, Y., Takegawa, N., Moteki, N., Imaru, J., Han, S., Nakayama, T., Oanh, N. T. K., Hu, M., Kim, Y. J., and Kita, K.: Stabilization of the Mass Absorp- tion Cross Section of Black Carbon for Filter-Based Absorption Photometry by the use of a Heated Inlet, Aerosol Sci. Technol., 43, 741-756, doi:10.1080/02786820902889879, 2009.

Kong, S., Han, B., Bai, Z., Chen, L., Shi, J., and Xu, Z.: Receptor modeling of $\mathrm{PM}_{2.5}, \mathrm{PM}_{10}$ and TSP in different seasons and long-range transport analysis at a coastal site of Tianjin, China., Sci. Total Environ., 408, 4681-94, doi:10.1016/j.scitotenv.2010.06.005, 2010.

Kreidenweis, S. M., Petters, M. D., and DeMott, P. J.: Singleparameter estimates of aerosol water content, Environ. Res. Lett., 3, 35002, doi:10.1088/1748-9326/3/3/035002, 2008.

Laden, F., Schwartz, J., Speizer, F. E., and Dockery, D. W.: Reduction in Fine Particulate Air Pollution and Mortality, Am. J. Respir. Crit. Care Med., 173, 667-672, doi:10.1164/rccm.200503-443OC, 2006.

Larson, T., Su, J., Baribeau, A.-M., Buzzelli, M., Setton, E., and Brauer, M.: A Spatial Model of Urban Winter Woodsmoke Concentrations, Environ. Sci. Technol., 41, 24292436, doi:10.1021/es0614060, 2007.

Lim, S. S., Vos, T., Flaxman, A. D., Danaei, G., Shibuya, K., AdairRohani, H., AlMazroa, M. A., Amann, M., Anderson, H. R., Andrews, K. G., Aryee, M., Atkinson, C., Bacchus, L. J., Bahalim, A. N., Balakrishnan, K., Balmes, J., Barker-Collo, S., Baxter, A., Bell, M. L., Blore, J. D., Blyth, F., Bonner, C., Borges, G., Bourne, R., Boussinesq, M., Brauer, M., Brooks, P., Bruce, N. G., Brunekreef, B., Bryan-Hancock, C., et al.: A comparative risk assessment of burden of disease and injury attributable to 67 risk factors and risk factor clusters in 21 regions, 1990-2010: a systematic analysis for the Global Burden of Disease Study 2010, Lancet, 380, 2224-2260, 2012.

Lippmann, M.: Toxicological and epidemiological studies of cardiovascular effects of ambient air fine particulate matter (PM2.5) and its chemical components: Coherence and public health implications, Crit. Rev. Toxicol., 44, 299-347, doi:10.3109/10408444.2013.861796, 2014.

Liu, C.-N., Awasthi, A., Hung, Y.-H., Gugamsetty, B., Tsai, C.-J., Wu, Y.-C., and Chen, C.-F.: Differences in 24-h average PM2.5 concentrations between the beta attenuation monitor (BAM) and the dichotomous sampler (Dichot), Atmos. Environ., 75, 341347, doi:10.1016/j.atmosenv.2013.04.062, 2013.

Liu, C.-N., Chen, S.-C., and Tsai, C.-J.: A Novel Multifilter PM10PM2.5 Sampler (MFPPS), Aerosol Sci. Technol., 45, 14801487, doi:10.1080/02786826.2011.602135, 2011.

Martins, J. V., Cieslak, J. D., and Remer, L. A.: A portable and rugged three wavelength integrating nephelometer for field measurements, AirPhoton Technical Note, 2015.

McInnes, L., Bergin, M., Ogren, J., and Schwartz, S.: Apportionment of light scattering and hygroscopic growth to aerosol composition, Geophys. Res. Lett., 25, 513-516, doi:10.1029/98GL00127, 1998.

Mishra, S. K. and Tripathi, S. N.: Modeling optical properties of mineral dust over the Indian Desert, J. Geophys. Res.-Atmos., 113, D23201, doi:10.1029/2008JD010048, 2008.

Motallebi, N., Taylor, C. A., Turkiewicz, K., and Croes, B. E.: Particulate Matter in California: Part 1 - Intercomparison of Several PM2.5, PM10-2.5, and PM10 Monitoring Networks, J. Air Waste Manage. Assoc., 53, 1509-1516, doi:10.1080/10473289.2003.10466322, 2003. 
Paciorek, C. and Liu, Y.: Limitations of Remotely-sensed Aerosol as a Spatial Proxy for Fine Particulate Matter, Environ. Health Perspect., 117, 904-909, 2009.

Padró, L. T., Moore, R. H., Zhang, X., Rastogi, N., Weber, R. J., and Nenes, A.: Mixing state and compositional effects on CCN activity and droplet growth kinetics of size-resolved $\mathrm{CCN}$ in an urban environment, Atmos. Chem. Phys., 12, 10239-10255, doi:10.5194/acp-12-10239-2012, 2012.

Parker, R. D., Buzzard, G. H., Dzubay, T. G., and Bell, J. P.: A two stage respirable aerosol sampler using nuclepore filters in series, Atmos. Environ., 11, 617-621, doi:10.1016/00046981(77)90114-7, 1977.

Punger, E. and West, J. J.: The effect of grid resolution on estimates of the burden of ozone and fine particulate matter on premature mortality in the USA, Air Qual. Atmos. Heal., 6, 563-573, doi:10.1007/s11869-013-0197-8, 2013.

Quincey, P., Butterfield, D., Green, D., Coyle, M., and Cape, J. N.: An evaluation of measurement methods for organic, elemental and black carbon in ambient air monitoring sites, Atmos. Environ., 43, 5085-5091, doi:10.1016/j.atmosenv.2009.06.041, 2009.

Remer, L. A., Kaufman, Y. J., Tanré, D., Mattoo, S., Chu, D. A., Martins, J. V, Li, R.-R., Ichoku, C., Levy, R. C., Kleidman, R. G., Eck, T. F., Vermote, E., and Holben, B. N.: The MODIS Aerosol Algorithm, Products, and Validation, J. Atmos. Sci., 62, 947-973, doi:10.1175/JAS3385.1, 2005.
Schwab, J. J., Felton, H. D., Rattigan, O. V., and Demerjian, K. L.: New York State Urban and Rural Measurements of Continuous PM2.5 Mass by FDMS, TEOM, and BAM, J. Air Waste Manage. Assoc., 56, 372-383, doi:10.1080/10473289.2006.10464523, 2006.

Thermo Scientific: 1405-D TEOM, Continuous Dichotomous Ambient Particulate Monitor, Thermo Fish. Sci. Inc., 1, available at: http://www.thermoscientific.com/ecomm/servlet/ productsdetail_11152__11960556_-1, last access: 13 June 2013.

USEPA: Quality Assurance Guidance Document 2.12. Monitoring $\mathrm{PM}_{2.5}$ in Ambient Air Using Designated Reference or Class 1 Equivalent Methods, 1998

van Donkelaar, A., Martin, R. V, Brauer, M., Kahn, R., Levy, R., Verduzco, C., and Villeneuve, P. J.: Global estimates of ambient fine particulate matter concentrations from satellite-based aerosol optical depth: development and application, Environ. Health Perspect., 118, 847-855, 2010.

WHO: Human exposure to air pollution, in Update of the World Air Quality Guidelines World Health Organization, 61-86, World Health Organization, Geneva, Switzerland, 2005.

Yang, F., Tan, J., Zhao, Q., Du, Z., He, K., Ma, Y., Duan, F., Chen, G., and Zhao, Q.: Characteristics of $\mathrm{PM}_{2.5}$ speciation in representative megacities and across China, Atmos. Chem. Phys., 11, 5207-5219, doi:10.5194/acp-11-5207-2011, 2011. 